University of Rhode Island

DigitalCommons@URI

Open Access Master's Theses

1997

\title{
Development and Validation of Decisional Balance and Processes of Change Inventories for Heavy, Episodic Drinking
}

Jason Edward Maddock

University of Rhode Island

Follow this and additional works at: https://digitalcommons.uri.edu/theses

\section{Recommended Citation}

Maddock, Jason Edward, "Development and Validation of Decisional Balance and Processes of Change Inventories for Heavy, Episodic Drinking" (1997). Open Access Master's Theses. Paper 1573.

https://digitalcommons.uri.edu/theses/1573

This Thesis is brought to you for free and open access by DigitalCommons@URI. It has been accepted for inclusion in Open Access Master's Theses by an authorized administrator of DigitalCommons@URI. For more information, please contact digitalcommons-group@uri.edu. 
DEVELOPMENT AND VALIDATION OF

DECISIONAL BALANCE AND PROCESSES OF CHANGE

INVENTORIES FOR HEAVY, EPISODIC DRINKING

BY

JASON EDWARD MADDOCK

A THESIS SUBMITTED IN PARTIAL FULFILLMENT OF THE

REQUIREMENTS FOR THE DEGREE OF

MASTER OF ARTS

IN

PSYCHOLOGY

THE UNIVERSITY OF RHODE ISLAND 


\begin{abstract}
The transtheoretical model of behavior change indicates that people who successfully change problem behaviors move through a series of stages of readiness to change. This model has been successfully applied to a wide range of health-related behaviors, but only limited work has been devoted to adapting this model to the cessation of heavy episodic drinking. The goals of the study were to develop measures of two of the key constructs of the model: a decisional balance inventory measuring the pros and cons of alcohol consumption and a processes of change instrument assessing techniques used to change heavy drinking behavior.
\end{abstract}

Three hundred and eighty-two college students completed questionnaires containing these two instruments as well as measures of quantity and frequency of alcohol intake, demographic information, and problems associated with alcohol use. Measurement development was conducted on these two scales using a split-half cross validation procedure and following sequential methods. Results were quite satisfactory for the decisional balance inventory. One of the stopping criteria (MAP) suggested a three component solution, but two other stopping criteria (PA, Scree) suggested only one. The two factor solution was retained, due to empirical and theoretical evidence. Cronbach's coefficient alpha and SEM modification indices were then examined to reduce the item set. Confirmatory analysis using SEM to test alternative models for this reduced item set resulted in the acceptance of an uncorrelated two factor model and a 16item scale measuring the pros and cons of alcohol use. This scale demonstrated 
concurrent validity by its strong association with measures of quantity and frequency of alcohol use, problems associated with alcohol use, and stage of change.

A processes of change instrument was also developed. Initial principal components analysis revealed only seven factors using the MAP criteria and five factors following the parallel analysis criteria. The scree procedure suggested only one factor. Structural equation modeling (SEM) was then used to improve this solution since the factors were expected to be highly correlated and higher order factors were hypothesized to exist. Several rounds of reevaluation of theoretical fit and concomitant item evaluation were performed, using Cronbach's coefficient alpha and SEM modification indices to inform decision making. The result was a 30 item scale that fits the data adequately. Confirmatory results concurred with this solution. This scale was judged to have marginal concurrent validity by its relationships with measures of quantity and frequency of alcohol use, problems associated with alcohol use, and stage of change.

Use of these scales as well as limitations and potential uses of these measures will be discussed. 


\section{ACKNOWLEDGMENT}

I would like to thank everyone that helped me complete this thesis. Thanks are due to Dr. Joseph Rossi, for his methodological support and guidance throughout this endeavor. Dr. Robert Laforge should also be recognized for his enthusiasm and understanding of the alcohol content area. I would also like to express my gratitude to Dr. Colleen Redding and Dr. Cynthia Willey, whose support and careful analysis of this project made it what it is. 
PREFACE

This thesis is part of a line of research based on the Transtheoretical Model of behavior change and is prepared in manuscript format. 


\section{TABLE OF CONTENTS}

ABSTRACT $i i$

ACKNOWLEDGMENT iv

PREFACE $v$

TABLE OF CONTENTS__ vi

LIST OF TABLES__ viii

LIST OF FIGURES__ $x$

INTRODUCTION ___ 1

Current solutions._ 2

The Transtheoretical Model __ 2

Stage of Change _. 4

Decisional Balance __ 5

Processes of Change ___ 5

Purpose and goals of this study __ 7

Method __ 7

Subjects _ 7

Instruments ___ 8

Demographic Assessment ___ 8

Stage of Change: Algorithmic Assessment ___ 8

Decisional Balance Questionnaire ___ 9

Processes of Change Questionnaire __ 9

Collegiate Alcohol Problem Scale (CAPS)__ 10

Analysis Plan 10

Item Analyses

Exploratory Analyses____ 11

Confirmatory Analyses ___ 12

External Validity __ 15

Results _ 15

Decisional Balance __ 16

Item Analyses __ 16

Exploratory Analysis _ 16

Confirmatory Analysis____ 18 
External Validity ___ 18

Processes of Change ___ 20

Item Analyses ___ 20

Exploratory Analysis __ 20

Confirmatory Analysis__ 21

Hierarchical Model Testing____ 22

External Validity ___ 23

Discussion ___ 24

Decisional Balance __ 24

Processes of Change __ 28

General Discussion___ 30

BIBLIOGRAPHY $\quad 62$ 


\section{LIST OF TABLES}

Table 1: Staging Algorithm For Reducing Alcohol To Prevent Problems

Table 2: Stage Of Change For Heavy, Episodic Drinking $N=343$

Table 3: Decisional Balance Items For Immoderate Drinking 35

Table 4: Processes Of Change Items For Immoderate Drinking 37

Table 5: Conceptual Definitions Of The Processes Of Change 39

Table 6: Collegiate Alcohol Problems Scale (Caps) $\quad 40$

Table 7: Maximum Likelihood Loadings For Decisional Balance - 2 Component Solution 41

Table 8: Fit Indices For Decisional Balance Structural Models $\quad 42$

Table 9: Summary Of Analyses Of Variance: F And P Values 43

Table 10: Means And Standard Deviations For The Decisional Balance Scales By Average Drinks Per Episode

Table 11: Means And Standard Deviations For The Decisional Balance Scales By Average Days Drinking Per Week

Table 12: Means And Standard Deviations For The Decisional Balance Scales By Maximum Drinks In The Last 30 Days

Table 13: Means And Standard Deviations For The Decisional Balance Scales By Gender

Table 14: Means And Standard Deviations For The Decisional Balance Scales By Stage Of Change 
Table 15: Coefficient Alpha For Final 30 - Item POC Measure, By Subscale

Table 16: Subscale Characteristics For Final 30-Item POC Measure

Table 17: Fit Indices For Processes Of Change Structural Models

Table 18: Maximum Likelihood Correlations Among The Processes Of Change

Table 19: Final 30 Item Processes Of Change Maximum Likelihood Loadings

Table 20: Fit Indices For Hierarchical Structural Models

Table 21: Correlations Among The Processes Of Change And External Variables 56

Table 22: Mean POC Subscales T Scores, By Stage Of Change 


\section{LIST OF FIGURES}

Figure 1: Structural Model For Uncorrelated Decisional Balance Scale

Figure 2: Decisional Balance Scales by Stage of Change

Figure 3: Hierarchical Loadings of the Processes of Change Scale

Figure 4: Higher Order Processes by Stage of Change 


\section{INTRODUCTION}

Heavy episodic or binge drinking poses serious health problems to the individual and others that come in contact with that individual. Alcohol accounts for 100,000 deaths per year (Robert Wood Johnson Foundation, 1996). Alcohol abuse has been implicated in almost half of motor vehicle fatalities (Robert Wood Johnson Foundation, 1993). Unsafe sex, a leading cause of STD's and AIDS, has also been associated with misuse of alcohol (Hanson \& Engs, 1992). Alcohol abuse is considered the number one problem on many campuses by college presidents (Wechsler, Davenport, Dowdall, Moeykens, \& Castillo, 1994). A large study of drinking on college campuses found that $44 \%$ of college students responding to the survey were binge drinkers, and $19 \%$ of them were frequent binge drinkers (Wechsler et al., 1994). Almost half of the binge drinkers in this study (Wechsler et al., 1994) reported having five or more drinking-related problems since the beginning of the school year, including unplanned sex and injuries. Other longitudinal studies have shown that the prevalence of heavy, episodic drinking peaks between the ages of 21-22 and drops thereafter (Johnson, O'Malley, \& Bachman, 1992). These studies demonstrate the immense problem of immoderate drinking among college students.

The fiscal costs associated with alcohol-problems in the U. S. has been estimated to be between 70.3 to 116 billion dollars a year (Harwood, Napolitano, Kristiansen, \& Collins, 1984; Rice, Kelman, Miller, \& Dunmeyer, 1990). Overall, these costs account for approximately $15 \%$ of the fiscal expenses of the U. S. health care system (Science, 
1983). Problems associated with drinking that are often experienced by college students include personal injury, accidents, missing classes, blackouts, legal difficulties, poorer academic performance, acquaintance rape, sexually transmitted diseases including AIDS, and unplanned pregnancy (Berkowitz \& Perkins, 1986; Engs \& Hanson, 1988; Gilksman, 1988; Meilman, Stone, Gaylor, \& Turco, 1990; Nicholi, 1985).

\section{Current solutions}

Because of these problems, most colleges have developed alcohol awareness or primary prevention programs designed to curb the incidence of unsafe drinking (Braucht \& Braucht, 1984): These programs have been successful in changing alcohol related knowledge and attitudes, but have shown little effectiveness in changing behavior (Kraft, 1984; Mills \& McCarty, 1983). No studies before 1989 using adequate controls and outcome measures have shown changes in drinking behavior among college students (Goodstadt, 1986; Moskowitz, 1989). More recent interventions have shown some reductions in self reported drinking, but are expensive, intensive, or show high noncompliance (Baer et al., 1992).

\section{The Transtheoretical Model}

The Transtheoretical model (TTM) of behavior change has been widely used to explain how people successfully change a problem behavior (Prochaska et al., 1994). The TTM has been applied to a wide variety of health related behaviors, including smoking cessation, cocaine use, condom use, dietary fat reduction, exercise adoption, weight control, ultraviolet light reduction, HIV prevention, and cessation of alcohol use 
among alcoholics (Prochaska \& DiClemente, 1985; Rosenbloom, 1991; Marcus, Rossi, Selby, Niaura, \& Abrams, 1992; Rossi, Rossi, Velicer, \& Prochaska, 1995; Redding, Rossi, Velicer, \& Prochaska, 1989; Rossi, Rossi, \& Prochaska, 1990; Rossi, 1990; Rossi, Blais, \& Weinstock, 1994; Prochaska, Redding, Harlow, Rossi, \& Velicer, 1994; DiClemente \& Hughes, 1990; Snow, 1991; Snow, Prochaska, \& Rossi, 1992). Interventions using the TTM have been successful, in part, because they are based directly on how people change on their own (Prochaska \& DiClemente, 1983, 1984, 1986; Prochaska, Velicer, Guadagnoli, \& Rossi, 1991). Current TTM interventions are stage matched to individuals in all three pre-action stages being intervened upon. Recent stage-matched interventions have employed individualized and interactive feedback using expert system reports (Prochaska, DiClemente, Velicer, \& Rossi, 1993; Velicer et al., 1993). This type of interactive intervention was able to outperform self help manuals, individualized self help manuals, and personalized counselor calls in a randomized study of smoking cessation (Prochaska, DiClemente, Velicer, \& Rossi, 1993). Development of TTM measures for heavy, episodic drinking would enable this type of intervention to be designed.

Research to date in the area of alcohol abuse has focused on the chronic abuse of alcohol, rather than on heavy, episodic drinking. Some developmental work in the area of binge drinking has been done with adolescents (Migneault, Pallonen, \& Velicer, 1997) and college students (Migneault, 1995). Application of the TTM to new content areas, such as immoderate drinking, relies upon development of psychometrically sound measures to assess the key constructs of the TTM. This study will focus on extending the 
work done in this area by developing and defining the decisional balance and processes of change scales for immoderate drinking. Earlier studies with these scales have had some success, but no definitive scales have been developed. This study will evaluate the robustness of these new scales for immoderate alcohol use while evaluating the TTM in this relatively new content area.

\section{Stage of Change}

Stage of change is the central organizing construct of the TTM. The model postulates that people move through a series of five stages of change in their attempts to modify their problem behaviors (Prochaska, DiClemente, \& Norcross, 1992). The five stages of change are precontemplation (not planning on changing), contemplation (considering change in the next six months), preparation (getting ready to change in the next month), action (currently changing), and maintenance (maintaining change for at least six months).

Stage of change has been assessed using both algorithmic measures and continuous measures. In the area of binge drinking, two algorithmic staging measures exist. One assesses readiness to stop binge drinking (Migneault, 1995). The other assesses readiness to limit alcohol to prevent problems (LaForge \& Maddock, 1997). However, while both of these measures show some validity with college populations, several weaknesses are still apparent in both (Laforge, Maddock, \& Rossi, 1998). 


\section{Decisional Balance}

Another of the main constructs of the TTM is decisional balance. This scale was originally developed from Janis \& Mann's $(1968,1977)$ conflict theory of decision making. It was adapted for the TTM for smoking cessation (Velicer, DiClemente, Prochaska, \& Brandenburg, 1985). Two studies have been conducted to develop a decisional balance scale among binge drinkers. The first (Migneault, Pallonen, \& Velicer, 1997) was developed using tenth and eleventh graders enrolled in vocational technical schools. A 16-item, psychometrically sound inventory was created. This inventory contained two components, the pros and cons of drinking. These items were then used in another study with college students (Migneault, 1995). This study yielded either a two or a three factor solution containing a pros factor and two cons factors. The cons factors were separated into actual and practical scale (labeled Cons-A) and potential and emotional scale (labeled Cons-P). The Cons-A scale contained only three items and had an Alpha of .62. Migneault (1995) decided to retain the three factor solution, so the Cons - A factor could be explored. Further developmental work needs to be conducted on this scale to try to provide a more definitive answer on the number of factors for this scale.

\section{Processes of Change}

A third construct of the TTM is the processes of change (POC), which is the use of different strategies to change a problem behavior (Prochaska \& DiClemente, 1983). Appropriate use of these processes has been shown to be a predictor of movement to the 
next stage of change (Prochaska et al., 1985). The POC have consistently been shown to have two higher order factors: an experiential factor, which contains processes that are cognitive and affective in nature, and a behavioral factor, that contains processes that are action oriented (Rossi, 1992). For smoking cessation, the use of experiential process has been shown to peak in the earlier stages, while the use of behavioral process peaks in the later stages (Prochaska, Velicer, DiClemente, \& Fava, 1988). Precontemplators have continually been shown to use the least amount of processes (DiClemente et al., 1991; Prochaska \& DiClemente, 1983; Prochaska, Velicer, Gaudagnoli, Rossi, \& DiClemente, 1991).

Only one study has looked at the POC for binge drinking (Migneault, 1995). This study attempted to develop a POC scale but had several problems. Twelve POC, as well as three processes of resistance were examined. Four of the twelve POC had low internal consistencies, and one process, social liberation, did not maintain its integrity as a separate process. These results may have been due to the methodology employed in this study, which relied solely on principal components analysis (PCA) and ignored structural equation modeling (SEM) in the exploratory phase. Sole reliance on PCA may lead to inconsistent results because the POC have been shown to be highly correlated and hierarchically organized. The best developed scales that exist for alcohol use were designed and normed on alcoholic populations (DiClemente, Carbonari, Addy, \& Velasquez, 1996; Snow, Prochaska, \& Rossi, 1994). These scales provide excellent internal consistency and validity for measuring POC among alcoholics and sober 
alcoholics in Alcoholics Anonymous, but extension to the binge drinking population is questionable.

Purpose and goals of this study

This study will attempt to develop well-defined, psychometrically sound instruments for decisional balance and processes of change of immoderate drinking. These constructs, in conjunction with stages of change and temptations to drink measures, will constitute measures of the core constructs of the TTM for immoderate drinking. Once all of these constructs are well developed, it is possible to begin conducting assessments and creating interventions for this behavior.

\section{Method}

$\underline{\text { Subjects }}$

Subjects were 382 introductory psychology students that completed an anonymous questionnaire on alcohol behavior and attitudes in the Fall of 1996 or the Spring of 1997 for class credit. This study was approved by the Internal Review Board at the University of Rhode Island and all students provided informed consent. Of this sample, $348(91 \%)$ reported having drank at all in the last year and were retained for further analysis. The sample was predominately white $(88 \%)$, female $(66 \%)$, middle class $(97 \%)$, freshman $(61 \%)$, and lived in residence halls $(70 \%)$. The average age of the sample was $19.3(\mathrm{SD}=3.5)$. Eighteen percent of the sample reported being a member of a fraternity or a sorority. 
The drinking in this sample was fairly heavy. Seventy-eight percent of the sample reported weekly drinking and more than half (52\%) of the sample reported drinking on at least two days in the typical week. Consuming four or more drinks during the average drinking occasion was reported by over $61 \%$ of the sample. Sixty-six percent of the sample reported drinking five or more drinks during a single episode in the previous month.

\section{$\underline{\text { Instruments }}$}

The survey administration contained 239 questions, of which five item groups are of specific interest to this study.

\section{Demographic Assessment}

A set of 11 items asked about basic demographic information and drinking history. Variables examined in this study include: age, gender, days in the typical week that alcohol was consumed (Days), the number of drinks consumed during a typical drinking occasion (Drinks), and the maximum number of drinks consumed on one occasion in the last month (Maximum Drinks).

\section{Stage of Change: Algorithmic Assessment}

The stage of change algorithm used in this study was developed concurrently by Laforge and Maddock (1997) to assess readiness to reduce alcohol consumption to prevent alcohol related problems. The algorithm included a definition of problems related to alcohol with five response categories indicating the subjects intention to limit 
their alcohol consumption for the purpose of preventing alcohol related problems. Tables 1 and 2 include this definition with the algorithm and its accompanying distribution. This algorithm was selected because it appears to be the best of the existing measures (Laforge, Maddock, \& Rossi, 1998).

\section{Decisional Balance Questionnaire}

A set of 40 items hypothesized to measure the pros or the cons of drinking were generated from the alcoholism literature (DiClemente \& Hughes, 1990) and from an earlier instrument developed on a college population (Migneault, 1995). Additional items were developed by the author to fully capture the possible range of considerations of college students. This resulted in a 40 item set, which included 22 hypothesized con items and 18 pro items designed to keep both the practical and emotional range of the construct. The large number of con items was used to try to capture the two cons factors if they exist. Participants were asked to rank the importance of each item in their decisions about how much they drank or whether they drank at all using a 5-point Likert scale with $1=$ Not at all important and $5=$ Extremely important. The items are listed in Table 3.

\section{Processes of Change Questionnaire}

A set of 40 items hypothesized to measure the ten POC of heavy, episodic drinking were adopted from a POC instrument normed on alcoholics (DiClemente, Carbonari, Addy, Velasquez, 1996). The items represented ten hypothesized processes and two higher order factors in concordance with other research on the TTM. Processes 
of resistance were not examined in this study. Earlier work (Migneault, 1995) demonstrated that two of these processes varied with change from pre-action to action, but did not differentiate between the pre-action stages. The other process of resistance, repression/denial did not hold up psychometrically. A thorough study of the processes of resistance is needed and is beyond the scope of this study. Subjects were asked to rate the frequency with which they engaged in or experienced each item in the last month using a 5-point Likert scale ranging from $1=$ Never and $5=$ Repeatedly. These items are listed in Table 4. The conceptual definitions of these processes are listed in Table 5.

\section{Collegiate Alcohol Problem Scale (CAPS)}

An eight item scale was developed to assess problems associated with heavy alcohol consumption (Maddock, Laforge, \& Rossi, 1997). Two factors assessing physical/emotional $(\alpha=.77)$ and social problems $(\alpha=.72)$ associated with alcohol use emerged. Subjects were asked to rate how often they had experienced any of the problems in the past year on a 5-point Likert scale ranging from $I=$ Never/Almost Never and $5=$ Very Often. These items are presented in Table 6 .

\section{Analysis Plan}

The instruments were developed using the sequential methods developed by Jackson (1970) and Comrey (1988). These methods follow a four step procedure: item analyses, exploratory analyses, confirmatory analyses, and external validation.

Item Analyses 
The analysis was begun by evaluating the scale statistics. Poor items, whose responses are marked by extreme distribution characteristics, such as a non-central mean, restriction in range, skewness, and kurtosis, were identified and eliminated.

\section{Exploratory Analyses}

The scales were developed using the split-half procedure in which the sample was randomly divided in half. The first half of the sample was selected for exploratory analysis. An exploratory principal components analysis (PCA) was conducted on the matrix of item intercorrelations generated from the first sample using pair-wise deletion. The number of components to retain was determined by comparing the results of three procedures that have been shown to be valid predictors of the correct dimensionally of an item set (Zwick \& Velicer, 1986). The Scree procedure (Catell, 1966), an improved procedure (Lautenschlager, 1989) for Parallel Analysis (Horn 1968), and the Minimum Average Partial method (Velicer, 1976). Both orthogonal (varimax) and oblique (direct quartimin) rotations were examined.

Since the scales have been hypothesized to be correlated and a more theoretical solution is desired to remain in line with other content areas, SEM was then conducted using the LISREL 7 structural modeling computer program (Joreskog \& Sorbom, 1989) to improve upon the PCA solution. Since SEM is based on theory, an a priori solution was imposed on the same initial matrix of item correlations. Several items with low loadings on their target factors were deleted. Decisions to delete further items were made by examining modification indices and normalized residuals, which revealed complex 
items and poorly functioning items. After items were deleted on empirical bases, additional items were eliminated by evaluating breadth of construct for the subscales.

\section{Confirmatory Analyses}

Confirmatory Factor Analysis including cross-validation and model testing of the factor structure delineated in the exploratory phase on Sample 1 was then conducted on Sample $2(n=168)$. SEM was conducted on the solution posited by the exploratory analyses. Coefficient alpha was also computed for the two scales.

To avoid confirmation bias, and as a further test of the adequacy of the structural factor model derived from the exploratory analyses in the first phase, several alternative measurement models representing different conceptualizations of the factor structure were evaluated to see which one best described the data. The alternate models for the decisional balance scale are:

1. Null Model - This is the simplest possible model, suggesting that there are no latent factors underlying the decisional balance of immoderate drinking and that all of the items are completely independent. This model is not meant as a serious representation of the data but rather is useful as a baseline against which other models may be compared.

2. One factor model - This model proposes the existence of only one factor with the pros and cons having bipolar loadings. Support for this model would indicate that the two factors are essentially opposite measures of the same construct.

3. Two-uncorrelated factor model - This model proposes the existence of two factors: the pros of drinking and the cons of drinking as independent of each other. 
4. Two correlated factor model - This model proposes the same existence of the two factors, but allows for some correlation between them. Support for this model would show that endorsement of one factor is related to endorsement of the other.

5. Three factor correlated model - This model proposes the existence of one pros factor, and two cons factors, actual and possible. Support for this model would demonstrate that drinkers differentiate between actual and possible problems associated with alcohol use.

The alternate models for the POC scale are:

1. Null Model - This model suggests that there are no latent factors underlying the POC and that all POC questionnaire items are completely independent. This model is not meant as a serious representation of the data but rather is useful as a baseline against which other models may be compared.

2. One factor model - This model proposes the existence of a single general POC factor for immoderate drinking. Support for this model would suggest that individuals do not differentiate among POC in trying to control their drinking.

3. Two factor model - This model proposes the existence of two factors, representing behavioral and experiential strategies. Support for this model would suggest that individuals differentiate among POC only at the level of the higher order factors.

4. Ten uncorrelated factors model - Support for this model would suggest that individuals can discriminate between the processes of change and use them independent of one another.

5. Ten correlated factors model - This model would follow the same rationale as the preceding one, but would allow for the processes to be correlated. Support for this model 
would suggest that individuals are able to discriminate between the processes but tend to use similar processes in concordance with each other. This model is expected to be the best fit for the data. Support for this model also suggests the existence of at least one higher order factor.

Measurement models were compared with maximum likelihood confirmatory factor analysis using LISREL 7 (Joreskog \& Sorbom, 1989). Evaluation of alternative models requires an assessment of the model's overall fit to the data (McDonald \& Marsh, 1990). Four indices of fit were computed and compared to determine goodness-of-fit, as recommended by Marsh, Balla, \& McDonald (1988). The maximum likelihood $\chi^{2}$ statistic is an absolute measure of fit (no reference is made to the null model) and, since it is highly dependent on sample size, will be used only as a basis of comparison with the other fit indices. The Root Mean Square Residual (RMSR) is another absolute index and is a measure of the non-fit of a model (Joreskog \& Sorbom, 1989). For these absolute indices $\left(\chi^{2}, \mathrm{RMSR}\right)$, lower values indicate better fit. For $\chi^{2}$, non-significant values are optimal. For RMSR, a value of .06 or less is considered an acceptable measure of fit, while $\chi^{2}$ is evaluated based on degrees of freedom and $\mathrm{p}$ values. The Tucker-Lewis nonnormed fit index (TLI; Tucker \& Lewis, 1973) and comparative fit index (CFI; Bentler, 1990) are both indices of relative fit as compared to the null model. Higher values indicate better fit for the relative indices (TLC, CFI) with " 1.0 " being a perfect fit and " 0 " indicating a complete lack of fit. Values of .90 are generally considered an excellent model fit while values less than .80 indicate the need for further improvement of model 
specifications. Parsimony requires that when two models fit equally well, the preferred model is the one with the fewest parameters.

\section{Construct Validity}

The scales were then examined for external validity. The relationship between the subscales to several variables were examined to judge the external validity of the instrument. The variables included age and gender, Greek membership, two alcohol related problem indices, stage of change and three alcohol consumption variables. Pearson- $R$ correlations were calculated for the continuous variables (age, the two problem indices, and Greek membership) and analysis of variance techniques were used for the categorical variables (gender, the alcohol consumption variables, and stage of change).

\section{Results}

\section{Subjects}

Subjects were 382 introductory psychology students that completed a questionnaire on alcohol behavior and attitudes in the Fall of 1996 or the Spring of 1997 for class credit. Of this sample, 348 (91\%) reported having drank at all in the last year and were retained for further analysis. The sample was predominately white $(88 \%)$, female (66\%), middle class $(97 \%)$, freshman (61\%), and lived in residence halls $(70 \%)$. The average age of the sample was $19.3(\mathrm{SD}=3.5)$. Eighteen percent of the sample reported being a member of a fraternity or a sorority.

The drinking in this sample was fairly heavy. Seventy-eight percent of the sample reported weekly drinking and more than half (52\%) of the sample reported drinking on at 
least two days in the typical week. Consuming four or more drinks during the average drinking occasion was reported by over $61 \%$ of the sample. Sixty-six percent of the sample reported drinking five or more drinks during a single episode in the previous month.

\section{Decisional Balance}

Item Analyses

Item analysis revealed that 39 of the 40 items showed fairly normal distribution with means ranging from 1.85 to 3.63 , and having standard deviations greater than 1 . One item was eliminated because of a low mean and standard deviation $(\mathrm{M}=1.59, \mathrm{SD}=$ 0.92). This item stated that the person got more respect from others because they could drink a lot. This item did not appear important to drinkers: sixty-three percent indicated that this was not at all important, and only $4.3 \%$ indicated that this was very or extremely important.

\section{Exploratory Analysis}

The first half of the sample $(\mathrm{N}=174)$ was selected for exploratory analysis. An exploratory principal components analysis (PCA) was conducted on the $39 \times 39$ matrix of item intercorrelations generated from this sample using pair-wise deletion $(\mathrm{N}=167)$. The Scree procedure (Catell, 1966) and an improved procedure (Lautenschlager, 1989) for Parallel Analysis (Horn 1968) indicated two components, while the Minimum Average Partial method (Velicer, 1976) suggested three. Both the two and three component 
solutions were investigated. Orthogonal (varimax) and oblique (direct quartimin) rotations were examined and found to be similar.

The three factor solution produced a pros factor and two cons factors. Three items did not load on any factor and nine items loaded at least .30 , on more than one factor. Of the remaining items, only four items loaded on the second cons factor. The factors accounted for $51 \%$ of the total variance. The two cons scales were difficult to interpret, but appear to be tapping actual and perceived cons of drinking. When the complex items were eliminated and the $27 \times 27$ matrix analyzed, scree, MAP, and parallel analysis indicated only two components. Theoretical and empirical support were found for the two factor solution, which was retained. The original $39 \times 39$ matrix was then used to confirm the two component solution. The two component solution clearly represented the Pros and Cons of alcohol use. Both oblique and orthogonal rotations were examined. These solutions produced virtually identical results and the varimax solution was chosen for further analysis. Four items were eliminated because of low loadings. This resulted in a 35 -item scale, with 21 items on the cons subscale and 14 items on the pros subscale. Corrected item total correlations were then computed for each item and those that decreased the alphas were removed. Item content was assessed before removal to ensure that the scale still encompassed the entire construct domain.

SEM was then used to validate and improve the PCA solution. The initial 35 item model provided poor fit to the data across all measures of model adequacy, $\chi^{2}(739)=$ $1623, \mathrm{RMSR}=.101, \mathrm{TLI}=.68, \mathrm{CFI}=.69 . \mathrm{A} 16 \mathrm{item}$ solution was established following the above procedure, with 8 items on each factor, $\chi^{2}(103)=162, \operatorname{RMSR}=.06, \mathrm{TLI}=.95$, 
CFI $=.95$. The two components explained $57 \%$ of the variance of the reduced item set. Items with maximum likelihood loadings are presented in Table 7. Cronbach's coefficient alpha (Cronbach, 1951) was .89 for the pros subscale and .89 for the cons subscale.

\section{Confirmatory Analysis}

Confirmatory analyses were then conducted on the second half of the sample ( $\mathrm{n}=$ 168). Coefficient alpha was computed for the two scales. The solutions were similar in Sample two. The alphas are .91 for the pros subscale and .84 for the cons subscale. Structural equation modeling (SEM) was conducted on the 16-item, 2 factor solution posited by the exploratory analyses to test the alternative model described above.

The four fit indices are computed for each model in Table 8. The two factor correlated model and the three factor correlated model both provided a good fit for the data across all of the measures of model adequacy. However, the uncorrelated model produced almost identical fit. Chi square difference test revealed no difference between the three factor model and the uncorrelated model $\left(\chi^{2}(3)=2, p>.05\right)$ or the two factor correlated model and the uncorrelated model $\left(\chi^{2}(1)=0, p>.05\right)$. All three were significantly better than the one factor model. Since these three models are all theoretically feasible, the uncorrelated model will be accepted as the more parsimonious solution. The uncorrelated model with maximum likelihood loadings is presented in Figure 1.

\section{Construct Validity}


The decisional balance scales were then examined for validity. Age had a small nonsignificant correlation with the pros $(r=-.07)$ and the cons $(r=.02)$. Almost $88 \%$ of the sample was between the ages of 18-21, and it may, therefore, be difficult to find trends within this limited range. Membership in a Greek organization had a small negative non-significant association with the pros $(r=-.10, p=.07)$ and a small nonsignificant positive relationship with the cons $(r=.09, \mathrm{p}=.09)$. The two problem scales were strongly correlated with the pros of drinking (physical/emotional problems $r=.46, p$ $<.001$ social problems $\mathrm{r}=.33, \mathrm{p}<.001)$. There was also a negative correlation with the cons for the social problems subscale $(r=-.15, \mathrm{p}<.01)$ and a non-significant relationship with the physical/emotional subscale $(r=.09, \mathrm{p}=.09)$.

The relationship between the decisional balance scales, stage of change, alcohol consumption and gender were then examined. Separate ANOVAs were conducted on the two decisional balance scales using gender, drinks per episode, drinking occasions per week, and maximum number of drinks in one episode during the last month as the independent variables. All ANOVAs were significant except for gender by the pros of drinking subscale. Table 9 displays the $\mathrm{E}, \mathrm{p}$, and $\eta^{2}$ (effect size) values. Table 10 displays the means and standard deviations of the pros and cons by the average drinks per occasion. Table 11 lists the means and standard deviations of the two subscales by the number of drinking episodes per week. The means and standard deviations of the two subscales by the maximum number of drinks in one occasion during the last month are given in Table 12. Table 13 shows the means and standard deviations of the two subscales by gender. Table 14 displays the means and standard deviations of the two 
subscales by stage of change. Figure 2 displays the relationship between stage of change and the pros and cons.

\section{Processes of Change}

\section{Item Analyses}

Item analysis of the 40 items revealed low endorsement for most of the processes. Twenty seven of the items had means of less than two, and 14 of the items had standard deviations less than one. This analysis indicated that the POC developed on alcoholics are not widely used by a heavy, episodic, non-alcoholic drinking population. Since the use of these processes was infrequent across almost all of the items, a decision was made to retain all of the items for the exploratory analysis since no particular items stood out as especially poor.

\section{Exploratory Analysis}

Exploratory analyses were conducted on the first half of the sample $(N=174)$. An exploratory principal components analysis (PCA) was conducted on the $40 \times 40$ matrix of item intercorrelations generated from this sample using pair-wise deletion $(\mathbb{N}=$ 167). The Scree procedure (Catell, 1966) indicated one strong factor. An improved procedure (Lautenschlager, 1989) for Parallel Analysis (Horn 1968) indicated five components, while the Minimum Average Partial (Velicer, 1976) suggested seven. All solutions from one to seven components were investigated and found to be nearly impossible to interpret. 
Structural equation modeling (SEM) was then conducted to improve upon the PCA solution. Since SEM is based on theoretical predictions, a ten factor correlated model solution was imposed on the same $40 \times 40$ matrix of item correlations.

The initial model provided poor fit to the data across all measures of model adequacy, $\chi^{2}(695)=1715.65, \mathrm{RMSR}=.091, \mathrm{TLI}=.71, \mathrm{CFI}=.75 . \quad \mathrm{A} 30$ item solution was established with two to four items loading on each factor, $\chi^{2}(306)=763$, RMSR $=$ $.064, \mathrm{TLI}=.83, \mathrm{CFI}=.86$. Table 15 lists internal consistency coefficients (alpha) for each of the ten processes subscales and Table 16 lists scale means and standard deviations.

\section{Confirmatory Analysis}

Confirmatory analysis was then conducted on the second half of the sample $(\mathrm{N}=$ 168) . Coefficient alpha was also computed for the two scales and is displayed in Table 14. Structural equation modeling (SEM) was conducted on the 30 -item, 10 factor solution posited by the exploratory analyses to test the alternative model described above.

The four fit indices are computed for each model in Table 17. As hypothesized, the ten correlated model provided the best fit to the data across all measures of model adequacy, $\chi^{2}(360)=664, \mathrm{RMSR}=.069, \mathrm{TLI}=.85, \mathrm{CFI}=.87$. A chi square difference test was performed to test whether this model was significantly better than the next best fitting model (two correlated factor model). Results indicated that the ten correlated factors model fit the data significantly better than the other models, $\chi^{2}$ difference $=540$, $d f$ difference $=45, \underline{p}<.001$. Correlations among the processes ranged from .220 to .874 
with an average correlation among the processes of .536 (median $=.514$; see Table 18). The confirmed 30 item solution and the maximum likelihood item factor loadings by sample are displayed in Table 19.

\section{Hierarchical Model Testing}

Correlated factors in structural model solutions imply that higher order factors exist. Thus, a series of SEM analyses were conducted testing the fit of hierarchical models designed to evaluate the existence of two higher order factors previously established in other content areas. These second order factors group the 10 individual processes into experiential and behavioral strategies of change. The strong correlations between the factors indicate that these higher order factors may exist for heavy, episodic drinking as well. Based on the data from the full sample, three hierarchical models were compared.

1. One hierarchical factor model. Support for this model would indicate that individuals who are changing their behavior tend to use the processes in concordance with each other without discriminating between the experiential and behavioral methods of change.

2. Two uncorrelated hierarchical factors model. Support for this model suggests that individuals separate behavioral methods of change from experiential ones and do not use these methods in concordance with each other.

3. Two correlated hierarchical factors model. Support for this model indicates that people differentiate between the two types of processes, but that they use these separate 
factors in concordance with each other. This model has been supported in other content areas.

The three model fit indices are presented in Table 20. The two uncorrelated factors model had an extremely high RMSR and was, therefore, rejected from further analysis. Both the one higher order factor model and the two correlated higher order factor model fit provided excellent fit to the data. A chi-square difference test was performed to see if these two models were significantly different. Results indicated that the two correlated higher order factors fit the data significantly better than the one hierarchical factor model, $\chi^{2}(1)=7.0, \mathfrak{p}<.01$.

All of the processes loaded quite strongly on their higher order factors. The two higher order factors were also highly correlated. Figure 3 displays this model.

\section{Construct Validity}

The POC scales were then examined for validity. The relationship between the ten scales to several variables were examined to judge the construct validity of the scale. Pearson-R correlations were calculated for age, the two problem indices, the alcohol consumption variables, gender and Greek membership and analysis of variance techniques were used for stage of change. Pearson-R correlations are presented in Table 21.

The relationship between the POC scales and stage of change was examined. ANOVAs were conducted on the ten POC scales using an algorithm staging people for readiness to change the amount of drinks consumed in a sitting, and an algorithm staging 
people for readiness to limit alcohol to avoid problems. A MANOVA indicated that the ten processes differed significantly by stage of change as indicated by Wilks' criterion, $\underline{F}$ $(4,320)=1.92, \mathrm{p}<.001, \eta^{2}=.210$. Table 22 presents $T$ score means, $\mathrm{p}$ values, and $\eta^{2}$ values for each of the ten POC by stage of change. The relationship between the higher order factors and stage of change is displayed in Figure 4.

\section{Discussion}

The study has successfully developed a psychometrically well defined decisional balance scale for use with a college student population. The success of these measures provides a replication for earlier studies using the TTM for heavy, episodic drinking. This research demonstrates replicability of the TTM across problem behaviors. The existence of two separate scales of decisional balance indicate that the TTM is applicable to the area of binge drinking. The result with the POC scale was less encouraging. The scale showed good factor structure and adequate internal consistencies. Unfortunately, the construct validity of this scale was poor indicating that college drinkers are not discriminated by their use of these POC.

\section{Decisional Balance}

The preceding results suggest that the decisional balance scale developed above adequately measures the pros and cons of a college population's attitudes toward heavy, episodic drinking. The results also suggest that the scales are psychometrically sound with good confirmatory fit indices, high item saturation, and high internal validity. 
External validation of these scales is promising. Many interesting aspects of the pros and cons of drinking are revealed by this analysis. The non-significant difference between the males and females on the pros scale indicates that both sexes recognize and place equal importance on the pros of drinking in their decision to drink. Females higher endorsement of the cons, may be a reason that they tend to binge less than the males. This finding may indicate that females see value in drinking to the same level as males, but constrain their drinking because they are more worried about problems arising from heavy alcohol use. However, these findings could also be due to differences in stage of change. Females are further along in the stages of change, which might account for these differences. A stage by sex MANOVA should be conducted to assess the impact of stage. Unfortunately, the limited number of subjects in the middle stages in this study do not provide enough power to conduct these analyses. Therefore, any conclusions about sex differences from this data set should be considered preliminary.

The pros show strong positive relationships to measures of alcohol consumption and problems. The negative relationship of the cons to these indices is not as strong. Many reasons may lead to this relationship not occurring. Since heavy drinking is the norm for many students in this population, the cons of alcohol may not be as salient as the pros. Also, it might be accepted that everyone knows the cons of drinking and while they are important, they are not as important as the perceived benefit (pros) of drinking. This result is in accordance with earlier work done by Migneault (1995) which also showed the pros to be a better predictor of heavy drinking and stage of change than the cons. 
Membership in the Greek system was not found to be significantly related to the pros and cons of alcohol use. One reason for this may be the young age of the sample. Over $60 \%$ of the participants are freshmen and over $85 \%$ are freshmen and sophomores. Many of these students have not yet been socialized into the Greek system. Only $5 \%$ of the sample lived in Greek housing, compared to $10 \%$ in Migneault's sample (1995). This low percentage of people leads to low power to detect relationships between variables.

The pros and cons subscales show an interesting relationship with stage of change for binge drinking. Both the pros and cons rise from the precontemplation to the preparation stage. In precontemplation, the pros are higher than the cons. The cons become higher than the pros in the preparation stage. In action and maintenance there is a large difference between the pros and the cons with the cons being much higher. The level of endorsement of the cons increases linearly from precontemplation to preparation, and then taper off in action and maintenance. The pros also rise linearly from precontemplation to preparation, and then drop off during action and maintenance. This relationship is depicted in Figure 2. This finding is contrary to much of the work using the TTM on other problem behaviors. It indicates that the preparation stage is a salient decision making point, where both the pros and cons are very important. The result of this decision is instrumental in moving a person into a less dangerous drinking behavior pattern. A note of caution should be made here. Since few subjects were in the middle stages, outliers could change the results dramatically, so these interpretations should only be tentatively accepted until these results are replicated. Also, the staging algorithm was 
first used in this study. Further examination of this algorithm is necessary to determine its validity.

Another point that needs to be addressed is that these items measure the pros of drinking and the cons of heavy drinking. This is an interesting theoretical point, since many researchers in this area follow a harm reduction model, where drinking is allowed, but heavy drinking is strongly discouraged. Unlike smoking, abstinence is not the goal. Of the behaviors to which the TTM has been applied, this behavior is similar to dietary fat reduction. Researchers in this area encourage reduction of dietary fat below a certain level (currently $30 \%$ ), but do not encourage total fat avoidance. In this area, the pros focus on the eating of high fat foods, but do not directly address the pros of a high fat diet. While asking questions designed to assess the pros of heavy drinking might be desired, it does not appear to be necessary. In areas such as ultraviolet (UV) reduction, instruments have been developed that assess the pros of UV exposure and the pros of UV reduction. This differs from the original theoretical conceptualization of the decisional balance inventory, but is easier for respondents to answer and has been shown to be a valid predictor of change. The pros of drinking in this study show a linear relationship to both measures of quantity and frequency of alcohol intake as well as problems associated with alcohol use. Changing the pros measure might change the focus to only extremely heavy drinkers and ignore those individuals with an external locus of control for drinking who get "carried away" at parties and never intend to drink as much as they do. Since good construct validity exists, the pros of drinking seem to be a reasonable measure for this population and problem area. 
The strong and weak principles were not replicated in this study (Prochaska, 1994). According to this principle, progression from precontemplation to action is a function of the cons of drinking increasing by one standard deviation, and the pros of drinking decreasing by one half standard deviation. Again, this could be a function of the staging algorithm and should not be considered a contradiction of the strong and weak principles.

\section{Processes of Change}

These results suggest that the POC scale does a less than adequate job of measuring the strategies used by a college population to change heavy, episodic drinking. The results suggest that the scales are psychometrically sound with good confirmatory fit indices, good item saturation, and acceptable internal consistencies. A limited item set at the outset led to the shortening of three of the scales to two items. While two item scales are undesirable, deletion of the third item was unavoidable in this situation. The poor fit of the 40 item model indicates that using measures designed on an alcoholic population for a binge drinking population is unwise and should be done with caution. However, good final results of the 30 item scale indicate that some of the items are valid across populations.

Close inspection of the data reveals many interesting facets of these scales. Most of the alphas are quite good. However, environmental reevaluation, counterconditioning, and reinforcement management have marginal internal consistencies. The means of all of the processes are fairly low. Behavioral techniques are used more often than experiential 
techniques. The mean for consciousness raising is the lowest. The reason for this may be that the scale is only two items and one of the items contains the idea of quitting drinking. This is expected not to be strongly endorsed in a college population. The correlations between the individual processes are quite high. Counterconditioning and reinforcement management have the highest correlation of .874 . Self liberation and self reevaluation have the second highest correlation .870 . These extremely high correlations indicate that college drinkers do not discriminate these processes from each other. This can be remedied in one of two ways, either by writing better items or merging the two processes. As this data indicates, keeping these processes separate adds little, if anything. The strong correlation of the two higher order factors indicate that there is little differentiation between behavioral and experiential techniques. Although the two factor higher order solution fits slightly better, it may be best to think of the processes as one factor correlated strategies.

Construct validation of these scales was limited. Although Social Liberation has not related to any of the external variables, the other processes showed some construct validation. The alcohol consumption variables showed negative correlations to seven of the processes. This indicates that the more people drink, the less likely they are to use the processes and vice versa. The social problem index was not significantly correlated to any of the processes. The physical problem index was positively correlated to six of the processes. This finding at first seems counterintuitive. However, this index asks about problems that occurred in the last year. These problems also tend to be more severe than the social problems. Since these problems have been severe in the past, heavy drinkers 
are using helping relationships and other processes to help avoid these situations in the future. Alternatively, these drinkers have more serious problems, they are the most like alcoholics, and need to use processes like counterconditioning more to stay out of trouble.

Age had no significant correlations with any of the POC. Membership in a Greek organization is negatively correlated with two of the processes: dramatic relief and helping relationships. In an organization that puts a strong emphasis on drinking, non drinking friends might be difficult to find. Expressions of emotional feelings about the problems of alcohol might be discouraged in an environment in which alcohol is the norm. Females use self reevaluation and stimulus control more than males do. However, none of the other processes are used significantly more by either sex.

Process use by stage of change revealed some significant differences mostly among the behavioral processes. At first, it appears that the experiential processes, with the exception of consciousness raising are not used differentially between the stages. This looks to be an artifact of the staging method, since most of the subjects are in the precontemplation and maintenance stages, differences in the middle stages are missed. Dramatic relief, environmental reevaluation, and self reevaluation peak during the middle stages and could be important differences pending validation of the staging algorithm.

\section{General Discussion}

This study replicates and advances earlier work done in this area. The resulting decisional balance scale shows good internal and external validity and is suggested for use in TTM interventions for heavy, episodic drinking. The results indicate that unlike 
earlier work in this area, the two factor solution is the best representation of the data. The two factor solution provides strong factors with the cons scale encompassing items from both the cons - a and cons - p scales. However, some validity still exists for two separate cons factors. The fit of the three factor model indicates that it is not a bad model, it is just not as parsimonious as the two factor model. An analysis of different types of drinkers may help clean up this confusion. It is possible that the actual cons of drinking may be more salient in preventing the acquisition of heavy drinking, while the practical cons might be more important in a stopping heavy drinking behavior. Longitudinal studies need to be performed to assess the predictive validity of these new scales. The POC is not recommended for use in its current form. An ideal POC measure should be developed using items written specifically for non-alcoholic populations. Additional work still needs to be completed on this scale.

Some important limitations exist in this study. The first and most important is that the POC items were adapted from the alcoholism literature. Although these items did reasonably well in the structural modeling context their means were especially low, indicating little use of the processes by most college students. Items specifically designed for the heavy, episodic, non-alcoholic population need to be more closely examined. The limited initial number of items in the original process scale is also a limitation. The staging algorithm is also a problem. Further studies need to be conducted to establish an algorithm that is reliable and valid for all college drinkers. Sample limitations should also be noted. This sample examined a cross-section of college students. These students proved to be predominately young, white, and middle 
class. Also, quantity and frequency measures of alcohol consumption have shown to underestimate the actual amount of alcohol consumed since it ignores episodic binges. To remedy these shortcomings, longitudinal studies need to be conducted on a more general population. These studies are necessary to determine the predictive validity of the TTM constructs in changing alcohol consumption patterns. Also, alcohol diaries, and calendar recall should be used to have a more sensitive measure of alcohol consumption.

In conclusion, this study has developed a valid and reliable scales for measuring decisional balance for heavy, episodic drinking. This work may help guide technologically innovative interventions which have been constructed for other problem behaviors (Velicer et al, 1993). Expert systems interventions using the TTM should prove to be especially useful for college drinkers, who tend to be highly saturated in the earlier stages of change and are highly technologically sophisticated. The use of expert systems could prove to be a solution for what is considered one of the biggest problems on college campuses today. 
Table 1: Staging Algorithm for Reducing_Alcohol to Prevent Problems

Problems related to alcohol use are not limited to alcohol addiction or 'alcoholism'. Most alcohol related problems occur infrequently to many drinkers, and are often a direct result of immoderate alcohol consumption (too many drinks on a single occasion). These include short term physical or emotional health problems, legal or social problems, and/or difficulties in relationships with family members, friends or co-workers. With this definition of alcohol related problems in mind...

Do you consistently limit the amount you drink to prevent alcohol related problems?

1. Yes, and I have for more than six months. $\rightarrow$ MAINTENANCE

2. Yes, but for less than six months. $\rightarrow$ ACTION

3. No, but I intend to in the next 30 days. $\rightarrow$ PREPARATION

4. No, but I intend to in the next six months. $\rightarrow$ CONTEMPLATION

5. No, and I do not intend to.

$\rightarrow$ PRECONTEMPLATION 
Table 2: Stage of change for heavy, episodic drinking $n=343$

\begin{tabular}{lrc}
\hline Stage & $\mathrm{N}$ & Percentage \\
\hline Precontemplation & 107 & $31.2 \%$ \\
Contemplation & 26 & $7.6 \%$ \\
Preparation & 13 & $3.8 \%$ \\
Action & 40 & $11.7 \%$ \\
Maintenance & 157 & $45.8 \%$ \\
\hline
\end{tabular}


Table 3: Decisional Balance Items for Immoderate Drinking

PRO 1 Drinking gives me a thrilling feeling.

CON 2 I might end up hurting somebody.

PRO 3 I am more self confident when I drink.

CON 4 Drinking could get me addicted to alcohol.

CON 5 Drinking could kill me.

PRO 6 Drinking gives me more courage.

CON $\quad 7$ I do not like myself as much when I drink.

$\begin{array}{lll}\text { PRO } & 8 & \text { Drinking makes me feel more independent. }\end{array}$

CON 9 Drinking makes me feel out of control.

PRO 10 I feel happier when I drink.

CON 11 Drinking could land me in trouble with the law.

CON 12 Some people try to avoid me when I drink.

PRO 13 I can talk with someone I am attracted to better after a few drinks.

PRO 14 Drinking helps keep my mind off problems.

CON 15 Drinking costs too much.

PRO 16 Drinking makes me more relaxed and less tense.

CON 17 Drinking is bad for my health.

CON 18 After drinking I often wake up feeling down.

PRO 19 Drinking could have beneficial effects on my health.

CON 20 Drinking too much makes me feel sick.

PRO 21 Drinking helps me have fun with friends.

CON 22 I waste the whole next day after drinking too much.

PRO 23 Drinking with friends is fun.

CON 24 Drinking could make it difficult for me to get home safely.

CON 25 I could embarrass myself when I drink too much.

CON 26 I can hurt people close to me when I drink too much.

PRO 27 I get more respect from others because I can drink a lot.

CON 28 Drinking too much could make me do things I regret.

PRO 29 Events with alcohol are more fun.

CON 30 My drinking causes problems with others.

PRO 31 When I drink my body feels better. 
CON 32 Some people close to me are disappointed in me because of my drinking.

$\mathrm{CON} 33$ I seem to get myself into trouble when drinking.

PRO 34 My drinking helps give me energy and keep me going.

PRO 35 Not drinking at a social gathering would make me feel too different.

CON 36 I could accidentally hurt someone because of my drinking.

PRO 37 I am more sure of myself when I am drinking.

CON $\quad 38 \quad$ I am setting a bad example for others with my drinking.

PRO 39 People seem to like me better when I am drinking.

CON 40 Drinking causes me to fail to do what is normally expected of me. 
Table 4: Processes of Change Items for Immoderate Drinking

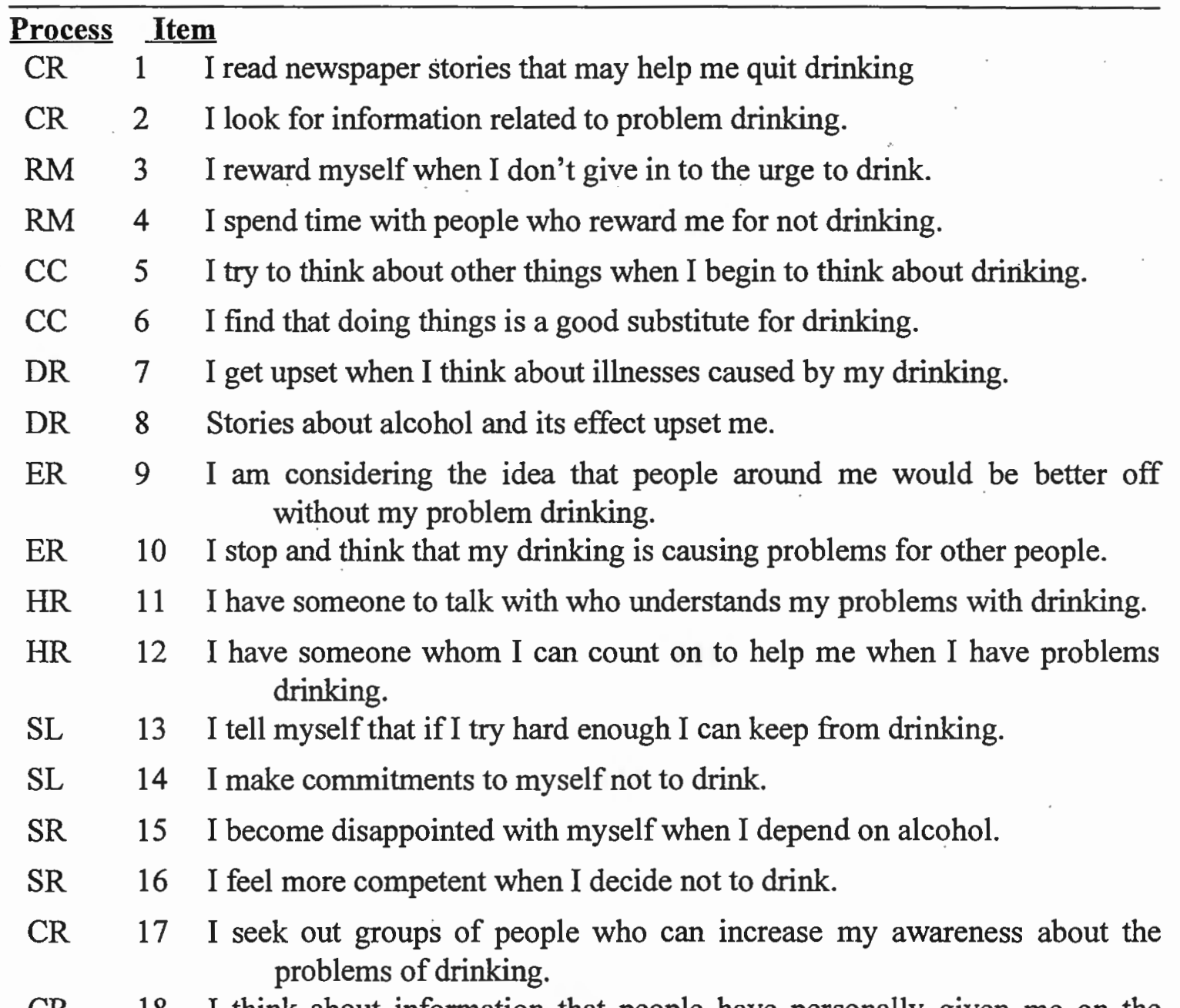

CR $\quad 18$ I think about information that people have personally given me on the benefits of quitting drinking.

RM 19 I do something nice for myself for making efforts to change.

RM 20 I don't let myself have fun when I drink.

CC 21 I calm myself when I get the urge to drink.

CC 22 I do something else instead of drinking when I need to deal with tension.

DR 23 Warnings about the health hazards of drinking have an emotional effect on me.

DR 24 I read newspaper stories that can effect me emotionally about my drinking.

ER 25 I stop to think how my drinking is hurting people around me.

ER 26 I have strong feelings about how much my drinking has hurt the people I care about.

HR 27 I can talk with at least one special person about my drinking experiences.. 
HR 28 I have someone who listens when I want to talk about my drinking.

SL $\quad 29$ I use will power to stop from drinking.

SL $\quad 30$ I make myself aware that I can overcome my drinking if I want to.

SR . 31 I consider that feeling good about myself includes changing my drinking behavior.

SR $\quad 32$ I think about the type of person I will be if I control my drinking.

SO 33 I find society changing in ways that makes it easier for me to overcome my drinking problem.

SO 34 I see advertisements on television about how society is trying to help people not to drink.

SC 35 I use reminders to help me not to drink.

SC $\quad 36$ I stay away from places generally associated with my drinking.

SO 37 I see signs in some public places trying to help people not to drink.

SO $\quad 38$ I notice that people with alcohol problems are making known their desire not to be pressed to drink.

SC 39 I remove things from my home or work that remind me of drinking.

SC 40 I avoid situations that encourage me to drink.

\begin{tabular}{|c|c|c|c|}
\hline & \multicolumn{3}{|c|}{ Key } \\
\hline & Experiential & & Behavioral \\
\hline $\mathbf{C R}$ & Consciousness Raising & $\mathrm{CC}$ & Counterconditioning \\
\hline$\overline{\mathbf{D R}}$ & Dramatic Relief & HR & Helping Relationships \\
\hline $\mathbf{E R}$ & Environmental Reevaluation & $\mathbf{R M}$ & Reinforcement Management \\
\hline SR & Self Reevaluation & SL & Self Liberation \\
\hline So & Social Liberation & SC & Stimulus Control \\
\hline
\end{tabular}


Table 5: Conceptual Definitions of the Processes of Change

\begin{tabular}{ll}
\hline Behavioral Processes & Definition \\
\hline Counterconditioning & Substitution of alternative behaviors for a problem behavior \\
Helping Relationships & Support from significant others, while attempting to change \\
$\begin{array}{l}\text { Self-Liberation } \\
\text { degree with }\end{array}$ & An individual's commitment to change and the \\
which they believe that this is possible
\end{tabular}

Stimulus Control Control of situations or cues that trigger the problem behavior

Reinforcement Management Rewards given by self or others for successful behavior change

\begin{tabular}{ll}
\hline Experiential Processes & Definition \\
\hline Consciousness Raising & $\begin{array}{l}\text { Making an effort to seek out and gain information about a } \\
\text { problem behavior }\end{array}$
\end{tabular}

Dramatic Relief

Strong emotional reactions to events in the social environment related to the behavior

Environmental Reevaluation Consideration and assessment of how the problem behavior effects the individual's physical and social

environments

Self-Reevaluation

Emotional and cognitive reappraisals of the costs and benefits of a problem behavior

Social Liberation

Awareness and acceptance of changes in the environment that provide alternatives to the problem behavior 
Table 6: Collegiate Alcohol Problems Scale (CAPS)

Use the scale below to rate HOW OFTEN you have had any of the following problems over the past year as a result of drinking alcoholic beverages.

1. Never/Almost Never

2. Seldom

3. Moderate Degree

4. Often

5. Never/Almost Never

Scale 1: Physical/Emotional Problems

1. Feeling sad, blue, or depressed

2. Nervousness, irritability

3. Caused you to feel bad about yourself

4. Problems with appetite or sleeping

Scale 2: Social Problems

1. Engaged in unplanned sexual activity

2. Drove under the influence

3. Did not use protection when engaging in sex

4. Illegal activities associated with drug use 
Table 7: Maximum likelihood loadings for exploratory analysis of decisional balance items - 2 component solution

Scale 1: Pros

Component

1. Drinking gives me more courage

2. I feel happier when I drink

.635

3. I can talk with someone I'm attracted to better after a few drinks $\quad .819$

4. Drinking helps keep my mind off problems

5. Drinking makes me more relaxed and less tense

6. Drinking helps me have fun with friends

7. When I drink my body feels better

8. I am more sure of myself when I am drinking

Scale 2: Cons

1. Drinking could get me addicted to alcohol

2. I do not like myself much when I drink

3. Drinking could land me in trouble with the law .781

4. Drinking is bad for my health $\quad .841$

5. Drinking too much could make me do things I regret .625

6. Some people close to me are disappointed in me because of my drinking $\quad .851$

7. I could accidentally hurt someone because of my drinking .628

8. I am setting a bad example for others with my drinking .640 
Table 8: Fit Indices for Decisional Balance Structural Models

\begin{tabular}{llllll}
\hline Type of Model & $\chi^{2}$ & df & TLI & CFI & RMSR \\
\hline Null & 1343 & 121 & $\cdots-$. &.-- & .32 \\
One Factor & 522 & 104 & .60 & .66 & .19 \\
2 Uncorrelated Factors & 157 & 104 & .95 & .96 & .06 \\
2 Correlated Factors & 157 & 103 & .95 & .96 & .06 \\
3 Correlated Factors & 155 & 101 & .95 & .96 & .06 \\
\hline
\end{tabular}


Table 9: Summary of analyses of variance: $F$ and $p$ values

\begin{tabular}{llrll}
\hline Effect & df & \multicolumn{1}{l}{ F } & p & $\eta^{2}$ \\
\hline Gender by pros & 1 & 0.18 & ns & --- \\
Gender by cons & 1 & 12.65 & .001 & .04 \\
Episodes by pros & 3 & 17.47 & .001 & .13 \\
Episodes by cons & 3 & 6.90 & .001 & .06 \\
Average drinks by pros & 4 & 20.37 & .001 & .19 \\
Average drinks by cons & 4 & 5.01 & .001 & .06 \\
Max. drinks by pros & 4 & 15.54 & .001 & .16 \\
Max. drinks by cons & 4 & 4.53 & .001 & .05 \\
Limit Alcohol Stage by pros & 4 & 11.96 & .001 & .13 \\
Limit Alcohol Stage by cons & 4 & 2.90 & .02 & .03 \\
\hline
\end{tabular}


Table 10: Means and standard deviations for the decisional balance scales by average drinks per episode.

\begin{tabular}{llllll}
\hline \multicolumn{5}{c}{ Decisional Balance Scales } \\
\hline \multirow{2}{*}{ Drinks per Episode } & \multicolumn{1}{c}{ Pros } & \multicolumn{1}{c}{ Cons } & \\
\hline none & Sean & SD & Mean & SD & $\mathrm{n}$ \\
1 to 2 & 11.79 & 5.32 & 25.28 & 10.71 & 28 \\
3 & 16.86 & 6.86 & 24.84 & 9.12 & 50 \\
4 & 19.94 & 6.82 & 22.08 & 7.83 & 53 \\
5 or more & 22.64 & 6.86 & 22.03 & 7.56 & 67 \\
\hline
\end{tabular}


Table 11: Means and standard deviations for the decisional balance scales by average days drinking per week.

\begin{tabular}{|c|c|c|c|c|}
\hline \multicolumn{5}{|c|}{ Decisional Balance Scales } \\
\hline & Pros & \multicolumn{2}{|c|}{ Cons } & \multirow[b]{2}{*}{$\mathrm{n}$} \\
\hline Drinks per Episode & Mean SD & Mean & SD & \\
\hline none & $15.78 \quad 6.99$ & 24.97 & 9.23 & 73 \\
\hline 1 & $19.88 \quad 7.37$ & 21.98 & 8.24 & 92 \\
\hline 2 to 3 & 23.00 & 21.38 & 6.92 & 137 \\
\hline 4 to 6 & 21.74 & 17.92 & 5.78 & 38 \\
\hline
\end{tabular}


Table 12: Means and standard deviations for the decisional balance scales by maximum drinks in the last 30 days.

\begin{tabular}{|c|c|c|c|}
\hline \multicolumn{4}{|c|}{ Decisional Balance Scales } \\
\hline Maximum Drinks & Pros & Cons & \\
\hline Last 30 Days & Mean SD & Mean SD & $\mathrm{n}$ \\
\hline none & $12.03 \quad 5.82$ & $\begin{array}{ll}25.63 & 10.27\end{array}$ & 27 \\
\hline 1 to 2 & 17.427 .11 & 24.939 .36 & 28 \\
\hline 3 to 4 & 19.23 & 22.078 .59 & 59 \\
\hline 5 to 9 & 22.03 & $22.03 \quad 7.24$ & 139 \\
\hline 10 or more & 22.41 & 19.56 & 87 \\
\hline
\end{tabular}


Table 13: Means and standard deviations for the decisional balance scales by gender.

\begin{tabular}{|c|c|c|c|c|c|}
\hline \multicolumn{6}{|c|}{ Decisional Balance Scales } \\
\hline \multirow[b]{2}{*}{ Gender } & \multicolumn{2}{|c|}{$\underline{\text { Pros }}$} & \multicolumn{2}{|c|}{ Cons } & \multirow[b]{2}{*}{$\mathrm{n}$} \\
\hline & Mean & $\mathrm{SD}$ & Mean & $\mathrm{SD}$ & \\
\hline Females & 20.73 & 7.37 & 23.06 & 7.80 & 224 \\
\hline Males & 20.36 & 7.53 & 19.85 & 7.87 & 116 \\
\hline
\end{tabular}


Table 14: Means and standard deviations for the Decisional Balance scales by Stage of Change

\begin{tabular}{|c|c|c|c|c|c|}
\hline \multicolumn{6}{|c|}{ Decisional Balance Scales } \\
\hline \multirow[b]{2}{*}{ Stage } & \multicolumn{2}{|c|}{ Pros } & \multicolumn{2}{|c|}{ Cons } & \multirow[b]{2}{*}{$\mathrm{n}$} \\
\hline & Mean & $\mathrm{SD}$ & Mean & SD & \\
\hline Precontemplation & 22.64 & 7.91 & 19.93 & 7.61 & 103 \\
\hline Contemplation & 21.31 & 5.56 & 21.73 & 7.15 & 26 \\
\hline Preparation & 25.53 & 8.37 & 24.69 & 4.07 & 13 \\
\hline Action & 23.52 & 7.59 & 22.40 & 6.57 & 40 \\
\hline Maintenance & 17.74 & 6.30 & 23.03 & 8.61 & 153 \\
\hline
\end{tabular}

\begin{tabular}{|c|c|c|c|}
\hline \multicolumn{4}{|c|}{ Decisional Balance Scales (T - scores) } \\
\hline & Pros & Cons & \\
\hline Stage & Mean SD & Mean SD & $\mathrm{n}$ \\
\hline Precontemplation & $\begin{array}{ll}52.87 & 10.6\end{array}$ & $47.47 \quad 9.6$ & 103 \\
\hline Contemplation & 51.127 .5 & $49.84 \quad 8.9$ & 26 \\
\hline Preparation & $\begin{array}{ll}56.82 & 11.3\end{array}$ & $53.55 \quad 5.1$ & 13 \\
\hline Action & $54.11 \quad 10.2$ & $50.68 \quad 8.3$ & 40 \\
\hline Maintenance & 46.338 .5 & $\begin{array}{ll}51.36 & 10.9\end{array}$ & 153 \\
\hline
\end{tabular}


Table 15: - Coefficient Alpha for final 30 - item POC measure, by subscale

\begin{tabular}{|c|c|c|c|c|}
\hline . & $\begin{array}{l}\text { Number } \\
\text { of items }\end{array}$ & $\begin{array}{l}\text { lst half } \\
\text { of sample } \\
(n=165)\end{array}$ & $\begin{array}{l}\text { 2nd half } \\
\text { of sample } \\
(n=165)\end{array}$ & $\begin{array}{l}\text { Total } \\
\text { sample } \\
(n=330)\end{array}$ \\
\hline 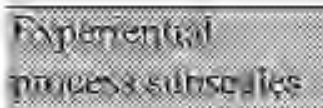 & 8 & 973 & 18 & 11 \\
\hline CR & 2 & .76 & .79 & .78 \\
\hline DR & 3 & .70 & .71 & .71 \\
\hline ER & 4 & .87 & .85 & .86 \\
\hline SR & 4 & .82 & .81 & .82 \\
\hline SO & 3 & .81 & .74 & .77 \\
\hline $\begin{array}{l}\text { Beliavional } \\
\text { process sulchales }\end{array}$ & 4 & 90 & 99 & 98 \\
\hline $\mathrm{CC}$ & 4 & .71 & .69 & .70 \\
\hline $\mathrm{HR}$ & 2 & .92 & .86 & .89 \\
\hline $\mathrm{RM}$ & 3 & .69 & .70 & .70 \\
\hline $\mathrm{SC}$ & 2 & .89 & .76 & .83 \\
\hline SL & 3 & .78 & .75 & .77 \\
\hline
\end{tabular}

\begin{tabular}{|c|c|c|c|}
\hline & \multicolumn{3}{|c|}{ Key } \\
\hline & Experiential & & Behavioral \\
\hline $\mathbf{C R}$ & Consciousness Raising & $\mathrm{CC}$ & Counterconditioning \\
\hline$\overline{\mathbf{D R}}$ & Dramatic Relief & $\overline{\text { HR }}$ & Helping Relationships \\
\hline ER & Environmental Reevaluation & $\mathbf{R M}$ & Reinforcement Management \\
\hline$\overline{\mathbf{S R}}$ & Self Reevaluation & $\overline{\text { SL }}$ & Self Liberation \\
\hline So & Social Liberation & $\mathbf{S C}$ & Stimulus Control \\
\hline
\end{tabular}


Table 16: Subscale Characteristics for final 30-item POC measure

\begin{tabular}{|c|c|c|c|c|}
\hline & \multicolumn{2}{|c|}{ Sample 1 } & \multicolumn{2}{|c|}{ Sample 2} \\
\hline & Mean & SD & Mean & SD \\
\hline $\begin{array}{l}\text { Expenienitial } \\
\text { nruosss sihsseale }\end{array}$ & 178 & 10.185 & 158 & 1065 \\
\hline $\mathrm{CR}$ & 1.40 & 0.71 & 1.53 & 0.84 \\
\hline DR & 2.11 & 0.91 & 2.22 & 0.90 \\
\hline ER & 1.54 & 0.79 & 1.59 & 0.84 \\
\hline SR & 1.77 & 1.20 & 1.90 & 0.98 \\
\hline SO & 2.01 & 0.93 & 2.12 & 0.93 \\
\hline 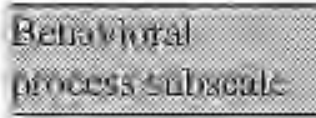 & 14 & 1070 & 2.13 & 078 \\
\hline $\mathrm{CC}$ & 2.04 & 0.84 & 2.20 & 0.85 \\
\hline HR & 2.51 & 1.45 & 2.79 & 1.44 \\
\hline RM & 1.52 & 1.09 & 1.71 & 0.83 \\
\hline $\mathrm{SC}$ & 1.76 & 1.09 & 1.73 & 0.92 \\
\hline SL & 2.14 & 1.12 & 2.25 & 1.16 \\
\hline
\end{tabular}

\begin{tabular}{|c|c|c|c|}
\hline & \multicolumn{3}{|c|}{ Key } \\
\hline & Experiential & & Behavioral \\
\hline$\overline{\mathbf{C R}}$ & Consciousness Raising & $\overline{C C}$ & Counterconditioning \\
\hline$\overline{\mathbf{D R}}$ & Dramatic Relief & $\overline{\text { HR }}$ & Helping Relationships \\
\hline ER & Environmental Reevaluation & $\overline{\mathbf{R M}}$ & Reinforcement Management \\
\hline $\mathbf{S R}$ & Self Reevaluation & $\overline{\mathrm{SL}}$ & Self Liberation \\
\hline S0 & Social Liberation & SC & Stimulus Control \\
\hline
\end{tabular}


Table 17: Fit Indices for Processes of Change Structural Models

\begin{tabular}{|c|c|c|c|c|c|c|}
\hline Type of Model & & & $\mathrm{df}$ & TLI & CFI & RMSR \\
\hline Null & 2831 & 435 & $\overline{----}$ & $\ldots$ & .320 & \\
\hline One Factor & 1279 & 405 & .61 & .64 & .094 & \\
\hline Two Factor & 1204 & 404 & .64 & .66 & .094 & \\
\hline 10 Uncorrelated Factors & 1377 & 405 & .56 & .60 & .289 & \\
\hline 10 Correlated Factors & 664 & 360 & .85 & .87 & .069 & \\
\hline
\end{tabular}


Table 18: Maximum Likelihood Correlations among the Processes of Change

\begin{tabular}{llllllllll}
\hline & CR & RM & CC & DR & ER & HR & SL & SR & SO \\
\hline RM & .647 & & & & & & & & \\
CC & .619 & .874 & & & & & & & \\
DR & .500 & .538 & .551 & & & & & & \\
ER & .527 & .461 & .599 & .427 & & & & & \\
HR & .409 & .387 & .422 & .456 & .374 & & & & \\
SL & .640 & .748 & .795 & .557 & .514 & .548 & & & \\
SR & .721 & .639 & .837 & .451 & .757 & .393 & .870 & & \\
SO & .448 & .220 & .349 & .234 & .285 & .387 & .353 & .370 & \\
SC & .632 & .633 & .701 & .452 & .262 & .323 & .666 & .623 & .338 \\
\hline
\end{tabular}

Range $=.220$ to .874

Mean $=.536$

Median $=.514$ 
Table 19: Final 30 item Processes of Change Maximum Likelihood Loadings

\begin{tabular}{|c|c|c|}
\hline 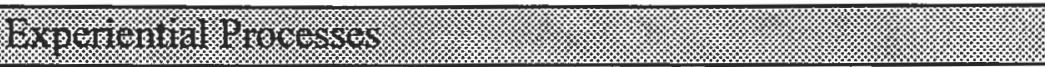 & Saniele & Simuple \\
\hline \multicolumn{3}{|l|}{ Consciousness Raising } \\
\hline $\begin{array}{l}\text { 1. I seek out groups of people who can increase my awareness } \\
\text { about the problems of drinking. }\end{array}$ & .759 & .776 \\
\hline $\begin{array}{l}\text { 2. I think about information that people have personally given } \\
\text { me on the benefits of quitting drinking. }\end{array}$ & .805 & .846 \\
\hline
\end{tabular}

\section{Dramatic Relief}

1. Stories about alcohol and its effects upset me.

.698

.624

2. Warnings about the health hazards of drinking have an emotional effect on me.

3. I read newspaper stories that can effect me emotionally about drinking.

\section{Environmental Reevaluation}

1. I am considering the idea that people around me would

be better off without my problem drinking.

2. I stop and think that my drinking is causing problems for other people.

3. I stop to think how my drinking is hurting people around me.

4. I have strong feelings about how much my drinking has hurt the people I care about.

\section{Self Reevaluation}

1. I become disappointed with myself when I depend on alcohol. $\quad .747 \quad .648$

2. I feel more competent when I decide not to drink. .708

3. I consider that feeling good about myself includes changing my drinking behavior.

4. I think about the type of person I will be if I control my drinking

\section{Social Liberation}

1. I make commitments to myself not to drink.

2. I use will power to stop from drinking.

3. I make myself aware that I can overcome my drinking if I want to.

\section{Behaniorall T r. oresses}

\section{Counterconditioning}

1. I try to think about other things when I begin to think about drinking.

2. I find that doing things is a good substitute for drinking.

3. I calm myself when I get the urge to drink.

4. I do something else instead of drinking when I need to deal with tension. 


\section{Helping Relationships}

1. I can talk with at least one special person about my

drinking experiences.

2. I have someone who listens when I want to talk about my drinking.

\section{Reinforcement Management}

1. I reward myself when I don't give in to the urge to drink.

2. I spend time with people who reward me for not drinking.

3. I do something nice for myself for making efforts to change.

\section{Self Liberation}

1. I make commitments to myself not to drink.

2. I use will power to stop from drinking. .800

3. I make myself aware that I can overcome my drinking if I want to.

drinking if I want to.

\section{Stimulus Control}

1. I stay away from places generally associated

with my drinking.

2. I avoid situations that encourage me to drink. 
Table 20: Fit Indices for Hierarchical Structural Models

Exploratory SEM on the Total Sample $(\mathrm{N}=330)$

\begin{tabular}{|c|c|c|c|c|c|c|}
\hline Type of Model & & & df & TLI & CFI & RMSR \\
\hline One Factor & 502 & 395 & .95 & .95 & .065 & \\
\hline Two Uncorrelated Factors & 656 & 395 & .88 & .87 & .224 & \\
\hline Two Correlated Factors & 495 & 394 & .96 & .95 & .065 & \\
\hline
\end{tabular}


Table 21: Correlations among the Processes of Change and External Variables

\begin{tabular}{|c|c|c|c|c|c|c|c|c|}
\hline & Days & Drink & Max & SP & $\mathrm{PP}$ & Age & Greek & Gender \\
\hline \multicolumn{9}{|c|}{ 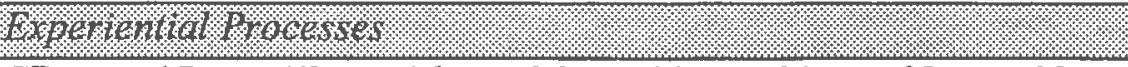 } \\
\hline $\mathrm{CR}$ & -.15 & -.17 & -.16 & -.06 & .08 & -.08 & -.02 & .03 \\
\hline DR & -.24 & -.16 & -.22 & -.06 & .09 & .01 & -.27 & -.01 \\
\hline ER & -.01 & -.09 & -.02 & .07 & .25 & .05 & .01 & .05 \\
\hline SR & -.17 & -.16 & -.22 & -.02 & .18 & -.00 & -.03 & .12 \\
\hline SO & .04 & .00 & .06 & -.01 & .08 & -.03 & -.10 & -.02 \\
\hline \multicolumn{9}{|c|}{ 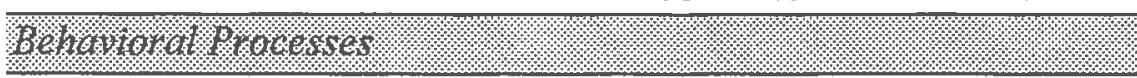 } \\
\hline $\mathrm{CC}$ & -.20 & -.18 & -.17 & -.10 & .15 & .04 & -.04 & .07 \\
\hline HR & -.02 & .04 & .01 & .02 & .18 & -.09 & -.18 & .04 \\
\hline $\mathrm{RM}$ & -.15 & -.13 & -.16 & -.01 & .27 & -.04 & -.07 & .08 \\
\hline SL & -.21 & -.22 & -.22 & -.10 & .08 & -.02 & -.01 & .10 \\
\hline $\mathrm{SC}$ & -.14 & -.17 & -.13 & -.00 & .20 & .05 & .04 & .12 \\
\hline
\end{tabular}

Note: Significant correlations in bold.

Key: Days $=$ Number of average drinking days per week; Drink $=$ Number of average drinks per episode; $\mathrm{Max}=$ Number of drinks consumed at largest episode in previous month. SP $=$ Social Problems; PP $=$ Physical Problems; Greek = Membership in Greek organizations. 
Table 22: Mean POC Subscales T Scores, by Stage of Change

\begin{tabular}{|c|c|c|c|c|c|c|c|}
\hline & & & Stage & & & $p$ & $\eta^{2}$ \\
\hline & $\mathrm{PC}$ & $\mathrm{C}$ & $\mathrm{P}$ & A & $\mathrm{M}$ & & \\
\hline \multicolumn{8}{|c|}{ H. } \\
\hline CR & 48.03 & 50.85 & 50.85 & 50.84 & 50.98 & .191 & ---.- \\
\hline DR & 47.11 & 52.49 & 51.22 & 49.11 & 51.88 & .002 & .048 \\
\hline ER & 49.20 & 52.16 & 57.49 & 50.20 & 49.60 & .051 & ---- \\
\hline SR & 47.65 & 51.45 & 52.85 & 51.79 & 50.76 & .573 & ----- \\
\hline $\mathrm{SO}$ & 49.70 & 49.74 & 51.89 & 48.06 & 51.83 & .048 & .028 \\
\hline \multicolumn{8}{|c|}{ 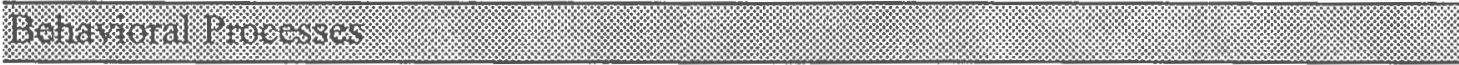 } \\
\hline $\mathrm{CC}$ & 47.29 & 48.08 & 51.89 & 49.95 & 51.83 & .005 & .044 \\
\hline HR & 49.71 & 49.35 & 52.95 & 51.28 & 49.75 & .722 & ........ \\
\hline $\mathrm{RM}$ & 46.97 & 50.12 & 53.69 & 51.93 & 51.31 & .003 & .048 \\
\hline $\mathrm{SC}$ & 46.93 & 48.64 & 50.18 & 51.97 & 51.87 & .001 & .051 \\
\hline SL & 46.89 & 48.64 & 52.52 & 53.12 & 51.37 & .001 & .054 \\
\hline
\end{tabular}




\section{Figure 1: Structural model for uncorrelated Decisional Balance scale .}
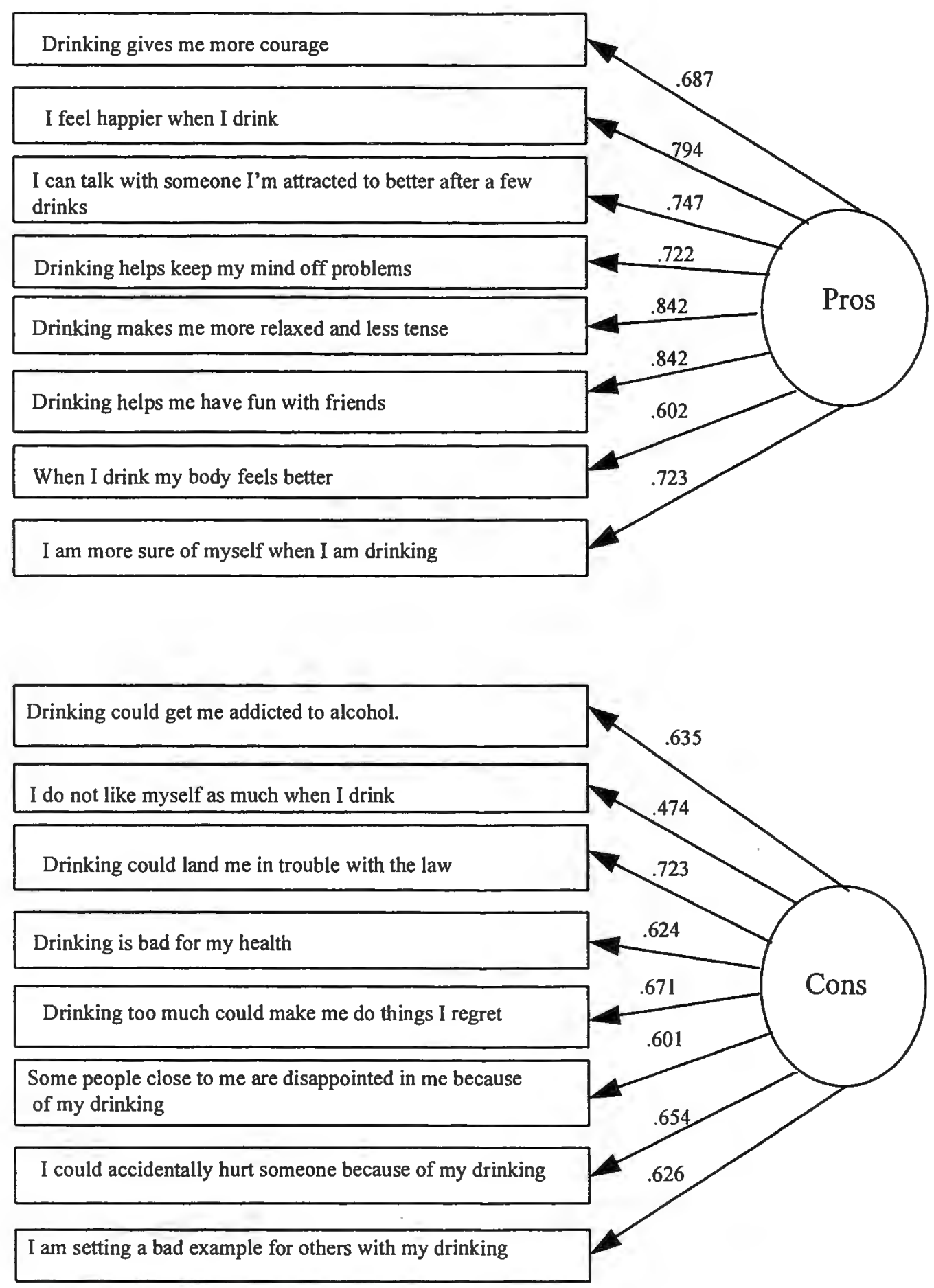
Figure 2: Decisional Balance Scales by Stage of Change

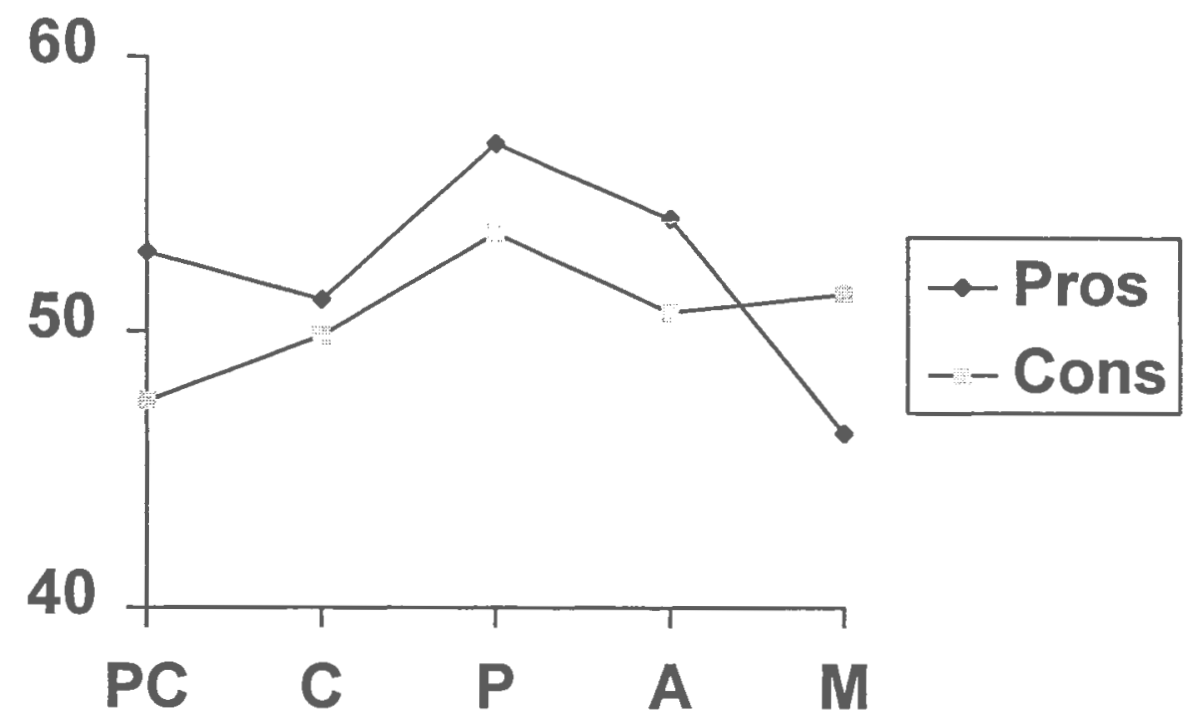


Figure 3: Hierarchical Loadings of the Processes of Change Scale

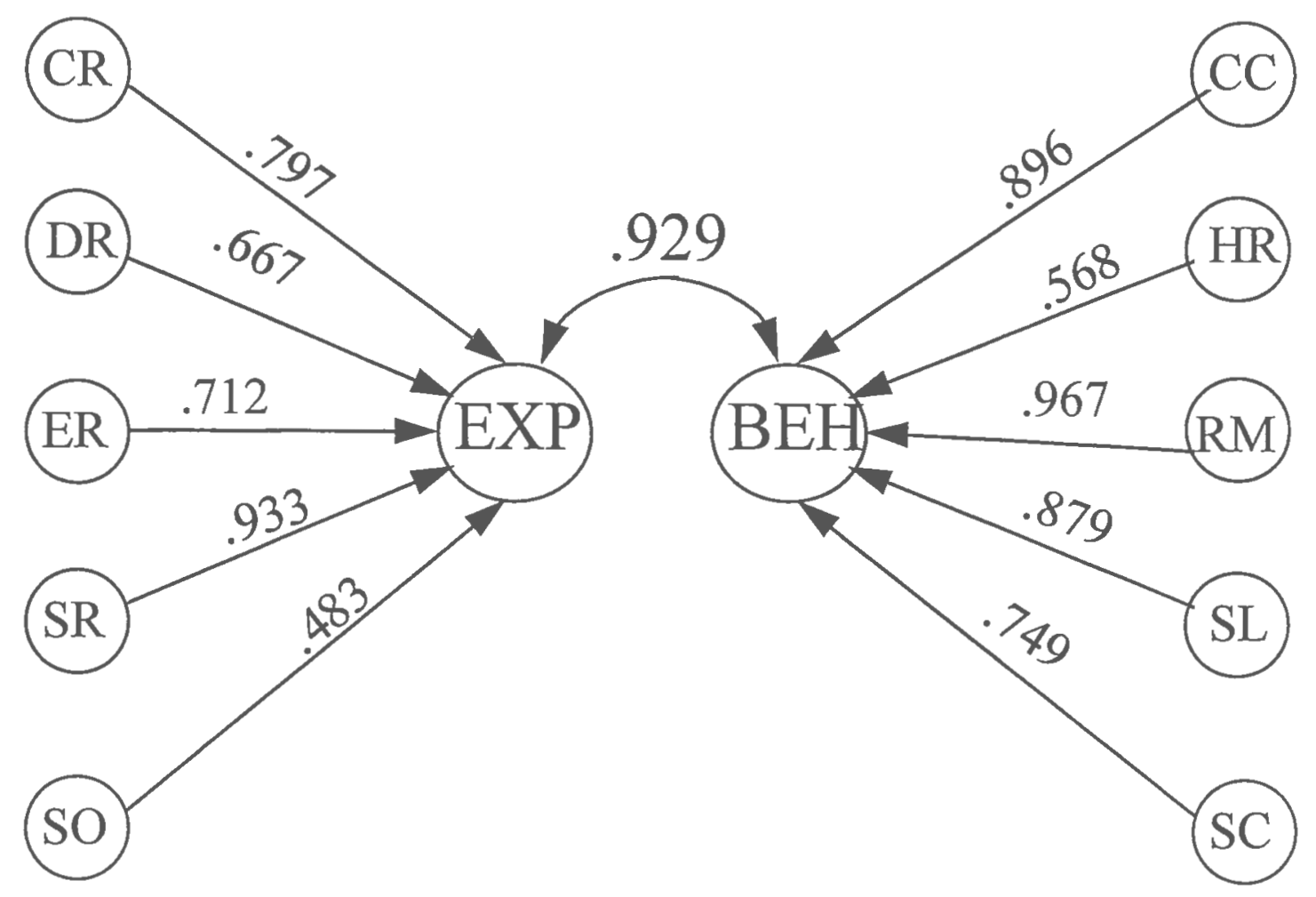


Figure 4: Higher Order Processes by Stage of Change

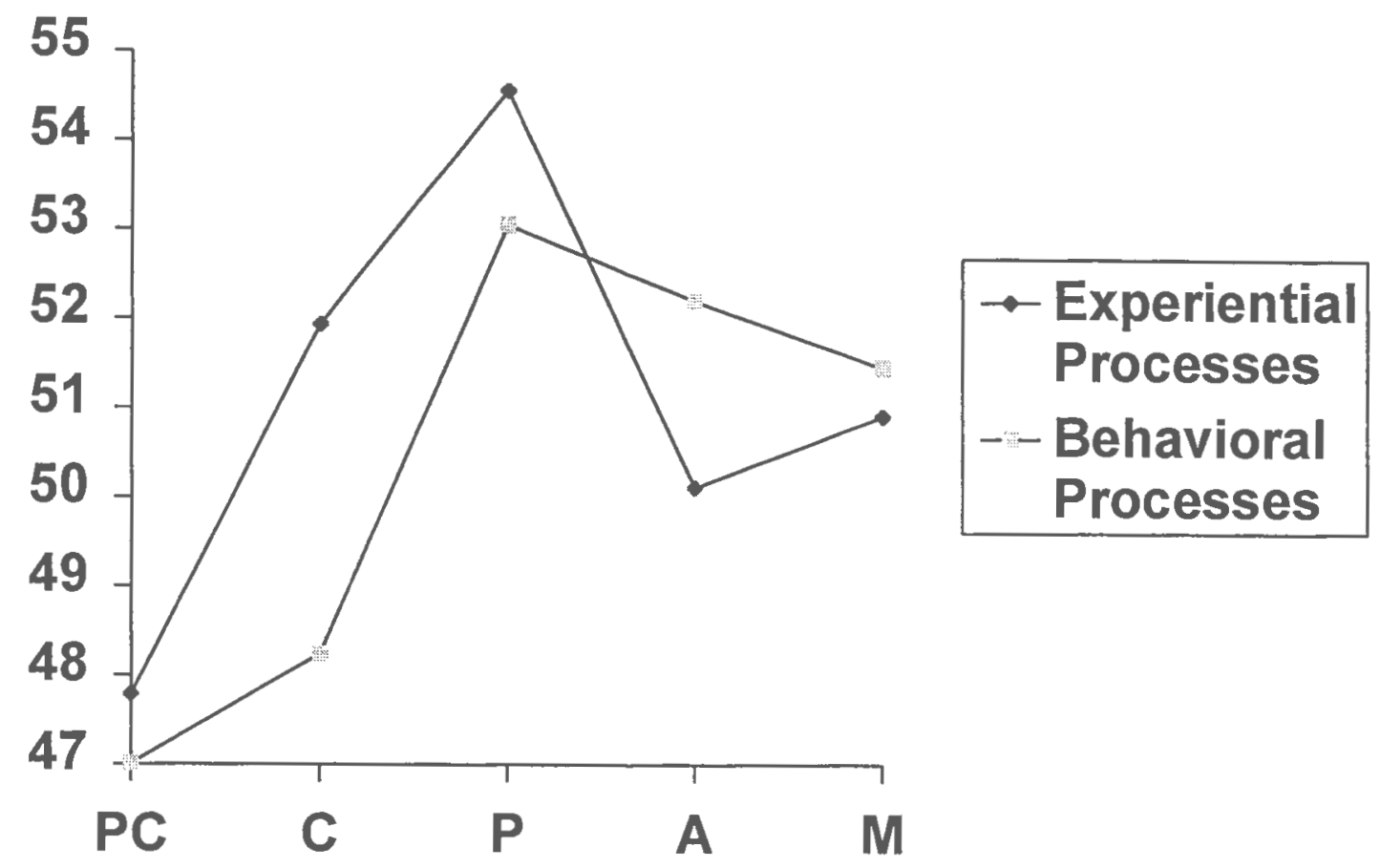




\section{BIBLIOGRAPHY}

Baer, J. S., Marlatt, G. A., Kivlahan, D. R., Fromme, K., Larimer, M. E., \& Williams, E. (1992). An experimental test of three methods of alcohol risk reduction with young adults. Journal of Consulting and Clinical Psychology, 60, 974-979.

Berkowitz, A. D., \& Perkins, H. W. (1986). Problem drinking among college students. American Journal of College Health, 35, 21-28.

Braucht, G. N., \& Braucht, B. (1984). Prevention of problem drinking among youth: Evaluation of educational strategies. In P. M. Miller \& T. D. Nirenburg (Eds.), Prevention of Alcohol Abuse (pp. 253-280). New York: Plenum Press.

Bentler, P. M. (1990). Comparative fit indices in structural models. Psychological Bulletin, 107, 238-246.

Cattell, R. B. (1966). The Scree test for the number of factors. Multivariate Behavioral Research, 1, 245-276.

Comrey, A. L. (1988). Factor-analytic methods of scale development in personality and clinical psychology. Journal of Consulting and Clinical Psychology, 56 $754-761$.

Cronbach, L. J. (1951). Coefficient alpha and the internal structure of tests. Psychometrika, 16, 297-334.

DiClemente, C. C., Carbonari, J. P., Addy, R. C., \& Velasquez, M. M. (1996, March). Alternative Short Forms of a Processes of Change Scale for Alcoholism 
Treatment. Poster presented at The Fourth International Congress on Behavioral Medicine, Washington, D. C.

DiClemente, C. C., \& Hughes, S. O. (1990). Stages of change profiles in outpatient alcoholism treatment. Journal of Substance Abuse, 2, 217-235.

DiClemente, C. C., Prochaska, J. O., Fairhurst, S. K., Velicer, W. F., Velasquez, M. M., \& Rossi, J. S. (1991). The process of smoking cessation: An analysis of precontemplation, contemplation, and preparation stages of change. $\underline{\text { Journal of }}$ Consulting and Clinical Psychology, 59, 295-304.

Engs, R. C. \& Hanson, D. J. (1988). University students' drinking patterns and problems: Examining the effects of raising the purchase age. Public Health Report, 103. 117-159.

Gilksman, L. (1988). Consequences of alcohol use: Behavior changes and problems during the first year of university. International Journal of the Addictions, 23 , 1281-1295.

Goodstadt, M. S. (1986). Alcohol education research \& practice: A logical analysis of two realities. Journal of Drug Education, 16, 349-365.

Hanson D. J. \& Engs, R. C. (1992). College students drinking problems: A national study, 1982-1991. Psychological Reports, 71, 39-42.

Harwood, H. J., Napolitano, D. M., Kristiansen, P. L., \& Collins, J. J., (1984). Economic Costs to Society of Alcohol and Drug Abuse and Mental Illness: 1980, Research Triangle Institute: Research Triangle Park, NC. 
Horn, J. I. (1965). A rationale and test for the number of factors in factor analysis. Psychometrika, 30, 179-185.

Jackson, D. (1970). A sequential system for personality scale development. In C. D. Spielberger (ed.), Current Topics in Clinical and Community Psychology Vol. 2. (pp. 61-96). New York: Academic Press.

Janis, I. L., \& Mann, L. (1968). A conflict-theory approach to attitude change and decision making. In A. Greenwald, T. Brook, T. Ostrom (Eds.), Psychological Foundation of Attitudes (pp. 327-360). New York: Academic Press.

Janis I. L. \& Mann, L. (1977). Decision Making: A Psychological Analysis of Conflict, Choices, and Commitment. New York: Academic Press.

Johnson, J. D., O’Malley, P. M., \& Bachman, J. G. (1992). Smoking, Drinking, and Illicit Drug use Among American Secondary School Students, College Students, and Young Adults, 1975-1991 (Vol. 2.). Washington, D. C.: National Institute on Drug Abuse.

Joreskog, K. G. \& Sorbom (1989). LISREL 7: A guide to the program and applications (2nd ed.). Chicago, IL: SPSS, Inc.

Kraft, D. P. (1984). A comprehensive prevention program for college students. In P. M. Miller \& T. D. Nirenburg (Eds.), Prevention of Alcohol Abuse (pp. 327-370). New York: Plenum Press.

Laforge, R. G. \& Maddock, J. E. (1997). [ Drinking Behaviors Study ]. Unpublished raw data. 
Laforge, R. G., Maddock, J. E. \& Rossi, J. S. (1998). Comparison of five stage methods for alcohol abuse among college students. Paper submitted for presentation at the 19th annual meeting of the Society of Behavioral Medicine, New Orleans, LA.

Lautenschlager, G. J. (1989). A comparison of alternatives to conducting Monte Carlo analyses for determining parallel analysis criteria. Multivariate Behavioral Research, 24 (3), 265-395.

Maddock, J. E., LaForge, R. G., \& Rossi, J. S. (1997). Development of a short. psychometrically reliable alcohol problem index for college students. Unpublished Manuscript.

Marcus, B. H., Rossi, J. S., Selby, V. C., Niaura, R. S. \& Abrams, D. B. (1992). The stages and processes of exercise adoption and maintenance in a work site sample. Health Psychology, 11 (6), 386-395.

Marsh, H. W., Balla, J. R., \& McDonald, R. P. (1988). Goodness-of-fit indices in confirmatory factor analysis: The effect of sample size. Psychological Bulletin. 103. 391-410.

McDonald, R. P. \& Marsh, H. W. (1990). Choosing a multivariate model: Noncentrality and goodness of fit. Psychological Bulletin, 107, 247-255.

Meilman, P. W., Stone, J. E., Gaylor, M. S., \& Turco, J. H. (1990). Alcohol consumption by college undergraduates: Current use and ten year trends. Journal of Studies on Alcohol, 51, 389-395.

Migneault, J. P. (1995). A Transtheoretical Approach to Immoderate Drinking in College. Unpublished doctoral dissertation. University of Rhode Island, Kingston, RI 
Migneault, J. P., Pallonen, U. E., \& Velicer, W. F. (1997). Decisional balance and stage of change. Addictive Behaviors, 22, 339-351.

Mills, K. C. \& McCarty, D. (1983). A data based alcohol abuse prevention program in a university setting. Journal of Alcohol and Drug Education, 28, 15-27.

Moskowitz, J. M. (1989). The primary prevention of alcohol problems: A critical review of the research literature. Journal of the Studies on Alcohol, 50, 54-88.

Nicholi, A. M. (1985). Characteristics of college students who use psychoactive drugs for non-medical reasons. Journal of American College Health, 33, 189-192.

Prochaska, J. O. (1994). Strong and weak principles for progressing from precontemplation to action based on twelve problem behaviors. Health Psychology, 13. 47-51.

Prochaska, J. O., \& DiClemente, C. C. (1983). Stages and processes of selfchange of smoking: Towards an integrative model of change. Journal of Consulting and Clinical Psychology, 51, 390-395.

Prochaska, J. O. \& DiClemente, C. C. (1984). The transtheoretical approach: Crossing the traditional boundaries of therapy. Homewood, IL: Irwin.

Prochaska, J. O. \& DiClemente, C. C. (1985). Common processes of self-change in smoking, weight control, and psychological distress. In S. Shiffman \& T. A. Wills (Eds.), Coping and Substance use (pp. 345-363). New York: Academic Press.

Prochaska, J. O. \& DiClemente, C. C. (1986). Towards a comprehensive model of change. In W. Miller \& N. Heather (Eds.), Treating Addictive Behaviors (pp. 3-27). New York: Plenum Press. 
Prochaska, J. O., DiClemente, C. C., \& Norcross, J. C. (1992). In search of how people change. American Psychologist, 47, 1102-1114.

Prochaska, J.O., DiClemente, C. C., Velicer, W. F., Ginpil, S., \& Norcross, J. C. (1985). Predicting change in smoking status for self changers. Addictive Behaviors, 10. 395-406.

Prochaska, J. O., DiClemente, C. C., Velicer, W. F., \& Rossi, J. S. (1993). Standardized, individualized, interactive and personalized self-help programs for smoking cessation. Health Psychology, 12, 399-405.

Prochaska, J. O., Redding, C. A., Harlow, L. L., Rossi, J. S. \& Velicer, W. F. (1994). The transtheoretical model and human immunodeficiency virus prevention: A review. Health Education Quarterly, 21(4), 471-486.

Prochaska, J. O., Velicer, W. F., DiClemente, C. C., \& Fava, J. (1988).

Measuring processes of change: Applications to the cessation of smoking. Journal of Consulting and Clinical Psychology, 56, 520-528.

Prochaska, J .O., Velicer, W. F., Gaudagnoli, E., Rossi, J. S., \& DiClemente, C. C. (1991). Patterns of change: Dynamic typologies applied to smoking cessation. Multivariate Behavioral Research, 26, 83-107.

Prochaska, J .O., Velicer, W. F., Rossi, J. S., Goldstein, M. G., Marcus, B. H., Rakowski, W., Fiore, C., Harlow, L., Redding, C. A., Rosenbloom, D., \& Rossi, S. R. (1994). Stages of change and decisional balance for twelve problem behaviors. Health Psychology. 13, 39-46. 
Redding, C. A., Rossi, J. S., Velicer, W. F., \& Prochaska, J. O. (1989, August). The Pros and Cons of Safer Sex: A Measurement Model. Paper presented at the 97 the annual convention of the American Psychological Association, New Orleans, LA.

Rice, D. P., Kelman, S., Miller, L. S., \& Dunmeyer, S. (1990). The Economics Costs of Alcohol and Drug Abuse and Mental Illness: National Institute on Drug Abuse, Rockville, MD.

Robert Wood Johnson Foundation. (1993). Substance Abuse: The Nation's Number One Health Problem, Key Indicators for Policy. Princeton, N. J. Robert Wood Johnson Foundation.

Robert Wood Johnson Foundation. (1996). Behavioral Determinants of Health. Princeton, N. J. Robert Wood Johnson Foundation.

Rosenbloom, D. (1991). A transtheoretical analysis of the stages and processes of change in cocaine users. Unpublished Doctoral Dissertation. University of Rhode Island, Kingston, RI.

Rossi, J. S. (1990, August). Radon and ultraviolet light exposure: Emerging cancer risk factors. In J. O. Prochaska (Chair), The Stages of Change; Extensions to New Areas of Behavior Change. Symposium presented at the 98th annual meeting of the American Psychological Association, Boston, MA.

Rossi, J. S. (1992, August). Common processes of change across nine problem behaviors. Paper presented at the 100th annual convention of the American Psychological Association, Washington, DC. 
Rossi, J. S., Blais, L. M., \& Weinstock, M. (1994). The Rhode Island Sun Smart Project: Skin cancer prevention reaches the beaches. American Journal of Public Health, 84, $1-3$.

Rossi, J. S., Rossi, S. R., Velicer, W. F., \& Prochaska, J. O. (1995). Motivational readiness to control weight. In D. B. Allison (Ed.), Handbook of assessment methods for eating behaviors and weight-related problems: Measurement, theory, and research. (pp. 387-430). Thousand Oaks, CA: Sage.

Rossi, S. R., Rossi, J. S. \& Prochaska, J. O. (1990, August). A stage model for reducing dietary fat. In J. O. Prochaska (Chair), The Stages of Change; Extensions to New Areas of Behavior Change. Symposium presented at the 98th annual meeting of the American Psychological Association, Boston, MA.

Science (1983). Is alcoholism treatment effective? 236, 20-22.

Snow, M. G. (1991). A transtheoretical analysis of strategies in the recovery process from alcoholic problems. Unpublished Doctoral Dissertation. University of Rhode Island, Kingston, RI.

Snow, M. G., Prochaska, J. O. \& Rossi, J. S. (1992). Stages of change for smoking cessation among former problem drinkers: A cross-sectional analysis. Journal of Substance Abuse, 4, 107-116.

Snow, M. G., Prochaska, J. O. \& Rossi, J. S. (1994). Processes of change in Alcoholics Anonymous: Maintenance factors in long-term sobriety. Journal of Studies on Alcohol, $55,362-371$. 
Tucker, L. R. \& Lewis, C. (1973). A reliability coefficient for maximum likelihood factor analysis. Psychometrika, 38, 1-10.

Velicer, W. F. (1976). Determining the number of components from the matrix of partial correlations. Psychometrika, 41, 321-327.

Velicer, W. F., DiClemente, C. C., Prochaska, J. O., \& Brandenburg, N. (1985). A decisional balance measure for assessing and predicting smoking status. $\underline{\text { Journal of }}$ Personality and Social Psychology, 48, 1279-1289.

Velicer, W. F., Prochaska, J. O., Bellis, J. M., DiClemente, C. C., Rossi, J. S., Fava, J. L., \& Steiger, J. H. (1993). An expert system intervention for smoking cessation. Psychological Bulletin, 111, 23-41.

Wechsler, H., Davenport, A., Dowdall, G., Moeykens, B., \& Castillo, S. (1994). Health and behavioral consequences of binge drinking in college. Journal of the American Medical Association, 272, 1672-1677.

Zwick, W. R. \& Velicer, W. F. (1986). A comparison of five rules for determining the number of components to retain. Psychological Bulletin, 99, 432-442. 